\title{
MULTICULTURALISMO Y EL DEBATE CONSTITUCIONAL CHILENO*
}

\author{
Multiculturalism and THE CHILEAN CONSTITUTIONAL DEBATE \\ Multiculturalisme eT le DÉBAT CONSTitutionnel CHILIEN
}

JAIME GAJARDO FALCÓN ${ }^{* *}$

\section{INTRODUCCIÓN Y ASPECTOS CONCEPTUALES}

El debate Constitucional en Chile se encuentra instalado tanto en el plano político como en el académico. Desde la academia los principales autores han argumentado sus posiciones 1 . La gran mayoría sostiene la necesidad de "reformar" la Constitución, teniendo diferencias en cuanto al alcance de la reforma y los mecanismos para realizarla ${ }^{2}$. En general, la doctrina sostiene la necesidad de que se

\footnotetext{
* Conferencia realizada en el "Primer encuentro de investigadores chilenos en Madrid", el día 17 de noviembre de 2014, en la Universidad Complutense de Madrid, España.

** Abogado. Licenciado en Ciencias Jurídicas y Sociales por la Universidad de Chile. Magíster en Derecho, con mención en Derecho Público por la Universidad de Chile. Máster en Gobernanza y Derechos Humanos por la Universidad Autónoma de Madrid, España. Máster en Derecho Constitucional, Centro de Estudios Políticos y Constitucionales. Doctorando en Derecho y Ciencia Política, Universidad Autónoma de Madrid, España. Actualmente se desempeña como Personal Investigador en Formación, en el Departamento de Derecho Público y Filosofía Jurídica de la Universidad Autónoma de Madrid, España y es Becario Chile para estudios doctorales en el extranjero. Correo electrónico: gajardofalcon@gmail.com.

${ }^{1}$ Para una recopilación y sistematización de las principales críticas y posturas sobre el alcance de la "reforma" y "cambio" Constitucional de la doctrina chilena, véase: Busch, Tania (2012). "El Concepto de Constitución y la Incomodidad Constitucional en Chile". Global Jurist, Vol. 12, pp. 1-38. Asimismo, véase: Atria, Fernando (2013a). La Constitución tramposa. Santiago: Lom Ediciones, pp. 15-103; Cfr. ZúNiga, Francisco (2012). "Nueva Constitución y Constitucionalismo en el Bicentenario". Revista de Derecho Público, No 76, pp. 125-145; Cfr. Ríos, Lautaro (2013). “¿Es necesaria una nueva Constitución?”. Revista de Derecho Público, No 78, pp. 205-222. Cfr. Ruiz-Tagle, Pablo (2009). "Un proyecto constitucional para la generación del bicentenario: Igualdad y derechos sociales y económicos en Chile”. En: Derecho y
} Humanidades, No 15, pp. 17-35.

${ }^{2}$ En cuanto a los mecanismos para una defensa de la Asamblea Constituyente, véase: Cfr. Atria (2013a), pp. 85-161; Por su parte, Francisco Zúñiga plantea la idea de una "operación constituyente", que pone en el centro del debate la necesidad de una "nueva constitución", la que puede ser conseguida mediante la utilización de distintos mecanismos. Cfr. ZúñIgA, Francisco (2013). "Nueva Constitución y Operación Constituyente. Algunas notas de acerca de la reforma constitucional y la asamblea constituyente". Estudios Constitucionales, No 1, pp. 511-540. Asimismo véase: ZúÑIGA, Francisco (2013). "Potestad Constituyente". Revista de Derecho. Escuela de Postgrado, No 5, pp. 307-318. En un sentido similar, véase: Ríos (2013), p. 221. Por su parte, Pablo Ruiz-Tagle descarta a la asamblea constituyente como mecanismo para lograr una "nueva" Constitución. En su defecto, considera que esta se debe realizar a través de un proceso continuo 
abra el techo ideológico de la Constitución y que se eliminen los enclaves contramayoritarios para que el autogobierno colectivo se pueda realizar adecuadamente ${ }^{3}$. Sin embargo, en cuanto al multiculturalismo el debate Constitucional ha sido débil y centrado en el reconocimiento de los derechos de los pueblos indígenas.

En razón de lo anterior, el objetivo principal del presente trabajo es reflexionar sobre el multiculturalismo en Chile y la necesidad de que este sea abordado normativamente en el actual debate Constitucional. Así las cosas, debo apuntar que para los efectos del presente trabajo hago la distinción entre el multiculturalismo entendido como hecho o fenómeno social y el multiculturalismo como propuesta normativa, es decir, de visión y enfoque político-jurídico para abordar el fenómeno. Considero que la distinción es útil, ya que, suele ocurrir que las diferencias académicas -y políticas- comiencen con malos entendidos conceptuales.

El multiculturalismo como hecho se entiende como el pluralismo de las culturas al interior de una sociedad política, esto es, de los universos simbólicos que confieren significado a las elecciones y a los planes de vida de aquellos que la habitan ${ }^{4}$. El multiculturalismo, entendido como un hecho o fenómeno social, es una realidad que se presenta en la mayoría de los países en el mundo ${ }^{5}$.

Las fuentes del fenómeno multicultural, según KYMLICKA, son de dos tipos. La primera fuente es la coexistencia dentro de un determinado Estado de más de una nación o pueblo. En esta primera fuente, se incluyen los Estados formados por más de una nación y aquellos que poseen pueblos indígenas en su interior. La segunda fuente del multiculturalismo es la inmigración. Un país será multicultural si presenta un gran número de individuos de otras culturas o nacionalidades, que hubieran llegado al país producto de la inmigración y mantengan algunas de sus particularidades culturales ${ }^{6}$.

La sociedad chilena no se encuentra exenta del fenómeno multicultural, es más, durante las últimas dos décadas hemos podido observar como se vuelve más porosa, con presencia de las dos fuentes multiculturales previamente identificadas y, por

de reformas constitucionales y un cambio en la interpretación constitucional (que abandone su vinculación originalista). Cfr. Ruzz-Tagle, Pablo (2008). "La trampa del neopresidencialismo: la Constitución 'Gatopardo"”. En: La República en Chile, Santiago: Lom Ediciones, pp. 197-218.

${ }^{3} \mathrm{Al}$ respecto, véase: Busch (2012), pp. 17-32.

${ }^{4}$ Cfr. Viola, Francesco (2003). "Constitución y multiculturalismo”. Ragion pratica, No 11, pp. 33-71. Entender el multiculturalismo, desde la óptica de pluralismo de las culturas, trae como consecuencia no incluir en el concepto los tipos de vida, movimientos sociales y asociaciones voluntarias de la sociedad civil, que otros sí incorporan. Estos grupos se pueden considerar de interés, a diferencia de los que surgen por las fuentes del multiculturalismo, que se denominarían grupos de tipo identitarios. Cfr. GuTmann, Amy (2008). La identidad en democracia [Identity in democracy]. Otero, Estela (Trad.), Buenos Aires: Katz Editores, pp. 61-126.

${ }^{5}$ En ese sentido apunta Amy Gutmann: “Todas las sociedades democráticas modernas contienen múltiples culturas en su interior. En ese sentido directo, las sociedades democráticas pueden llamarse multiculturales". Cfr. GutMann (2008), p. 68.

${ }^{6}$ Kymlicka, Will (1995). Multicultural Citizenship. Oxford: Oxford University Press, pp. 10-11. 
ende, tornándose el desafío multicultural más complejo de gestionar. Así, la población indígena es aproximadamente un $8 \%$ del total de habitantes de la república. Entre ellos, Mapuches, Rapa Nui, Aymaras, Atacameños, Diaguitas o Yaganes ${ }^{7}$. En lo relativo a la inmigración, según los datos del Departamento de Extranjería e Inmigración, del Ministerio del Interior y Seguridad Pública, la inmigración ha aumentado significativamente en la última década ${ }^{8}$. Si el año 2000 se entregaron 188 cartas de nacionalización, el año 2010, se cuadruplicaron, con un total de 7419. En lo referente a permisos de residencias permanentes o temporales, éstos también han aumentado considerablemente. Según el censo de población del año 2002 existía un total de población extranjera residente en Chile de 184.464 personas, las que al año 2009, según la estadística del DEM serían 352.344 personas. Estas cifras indican que alrededor del 2,08\% del total de la población residente en el país es extranjera. Dentro de este grupo se destaca la población de origen fronterizo, que agrupa a más del $61 \%$ del total de inmigrantes: la comunidad peruana con un $37,1 \%$ del total; la comunidad argentina con un $17,2 \%$; y la boliviana con un $6,8 \%{ }^{10}$.

Siendo Chile un país multicultural, debido a la presencia de pueblos indígenas y un número considerable y en aumento de inmigrantes, no se reconoce como tal y el tratamiento normativo del fenómeno ha sido débil y deficitario. A ello se deben sumar la falta de reconocimiento y menosprecio a la cultura de los pueblos originarios, la criminalización de sus movimientos y demandas, y la usurpación de territorio del que han sido víctimas los pueblos indígenas por parte del Estado de forma histórica ${ }^{11}$. Todo ello ha implicado que el "conflicto indígena" y especialmente el que existe con el pueblo mapuche se encuentre dotado de una gran carga simbólica y una desconfianza severa por parte de los pueblos indígenas hacia las autoridades gubernamentales ${ }^{12}$.

\footnotetext{
7 Según el censo del año 2012, la población chilena que se autoidentificaba como indígena aumentó considerablemente, del $8 \%$ al 11,11\% (1.714.677 personas). Lamentablemente dichas cifras se encuentran en revisión debido a los graves errores cometidos en el proceso censal.

${ }^{8} \mathrm{Al}$ respecto véase: MACHIN, Macarena (2011). Los derechos humanos y la migración en Chile. Disponible en: $<$ http://www.observatorio.cl/sites/default/files/biblioteca/resumen_ejecutivo_informe_migrantes_noviembre_2011.pdf > [Consulta: 20 octubre 2014].

9 Sobre la migración y el mercado laboral chileno, véase las interesantes estadísticas que se presentan en: Gammage, Sarah y Helmreich, Anne (2013). "Migración y mercados laborales en Chile: un trabajo decente para todos". En: Un Chile abierto: propuestas para una nueva Ley de Migración, No 2, Santiago: Centro Democracia y Comunidad, pp. 38-61.

${ }^{10}$ Según el censo del año 2012, la población chilena de origen extranjero aumentó, representando el 2,1\% del total de la población (339.536 personas). Lamentablemente dichas cifras se encuentran en revisión debido a los graves errores cometidos en el proceso censal.

${ }^{11}$ Sobre el conflicto indígena en términos amplios y con una visión panorámica de sus principales aspectos en Latinoamérica, véase: BengOA, José (2007). La emergencia indígena en América Latina. Santiago: Fondo de Cultura Económica, 343 pp.

${ }_{12} \mathrm{Al}$ respecto, véase: EgAÑA, Rodrigo (Ed.) (2008). Informe de la Comisión Verdad Histórica y Nuevo Trato con los Pueblos Indígenas. Santiago: Comisionado presidencial para Asuntos Indígenas, 684 pp.
} 
Ahora bien, desde un punto de vista estrictamente normativo, caben las siguientes preguntas: ¿Cómo abordar el fenómeno multicultural desde el derecho? ¿Es necesario un enfoque diferente a la conocida fórmula de igualdad y no discriminación? ¿Es necesario que la Constitución establezca normas especiales para los pueblos indígenas o en materia migratoria?

Para responder las preguntas planteadas, previamente es necesario señalar que ahora transitamos al nivel normativo del multiculturalismo, es decir, a los enfoques que se han dado desde la filosofía política y jurídica al fenómeno en cuestión. En ese sentido, las respuestas al hecho multicultural han venido tanto del liberalismo (cultural) ${ }^{13}$, comunitarismo ${ }^{14}$ e interculturalismo ${ }^{15}$. En este pla${ }_{13}$ El liberalismo cultural se encuentra integrado por dos variantes del liberalismo, a las cuales Kymlicka
ha identificado como nacionalismo liberal (J. Raz) y multiculturalismo liberal. El culturalismo liberal sería
la perspectiva que sostiene que el Estado liberal democrático no sólo debería hacer respetar los derechos
políticos y civiles de ciudadanía que amparan todas las democracias liberales, sino que también, deben
adoptar varios derechos específicos de grupo o políticas dirigidas a reconocer y a acomodar las diferentes
identidades y necesidades de los grupos etnoculturales. El culturalismo liberal, implica el paso de un Estado
liberal neutro en lo cultural a uno protector de los grupos etnoculturales que viven en su interior, el cual
adoptaría derechos específicos para los grupos y políticas de reconocimiento. Al respecto, véase: KYMLICKA,
Will (2001). Politics in the vernacular. Oxford: Oxford University Press, pp. 62-63.

${ }^{14}$ El enfoque comunitarista, en rasgos generales, plantea una política basada en la relevancia de la comunidad y su reconocimiento en el valor intrínseco para la identidad de los individuos. Asimismo, aboga por un reconocimiento y valoración de los grupos étnicos y culturales y critica al liberalismo por su pretensión de neutralidad. Para Charles Taylor (un comunitarista moderado), plantea la política del reconocimiento, que sería la discriminación a la inversa es defendida como una medida temporal que gradualmente nivelará las cosas y permitirá que las reglas supuestamente neutras retornen con todo su vigor, en tal forma que no discriminen a nadie. Este argumento parece bastante convincente ahí donde su base fáctica es sólida, sin embargo, no justificará algunas de las medidas que hoy se piden en nombre de la diferencia, y cuyo objeto no es el de construir un espacio social sin diferencias o neutro, sino, conservar y atender a las distinciones. Al fin y al cabo -se pregunta el autor-si la identidad es lo que nos preocupa, ¿entonces qué es más legítimo que nuestra aspiración a nunca perderla? Cfr. TAYLOR, Charles (1994). "The Politics of Recognition". En: Multiculturalism, Princeton: Princeton University Press, pp. 25-73.

15 El enfoque intercultural tiene distintas versiones, presentando diferencias internas importantes. Así, podemos anotar al menos tres versiones del interculturalismo: canadiense, europeo y latinoamericano. Para los efectos del presente trabajo, y a modo de simplificación del asunto, cuando me refiera a interculturalismo hablo de su versión latinoamericana. En un trabajo reciente Edwin Cruz señala que: "La categoría de interculturalidad se elaboró en una crítica al multiculturalismo anglosajón que comprende cuatro aspectos: una crítica metodológica contra la concepción esencialista de la identidad colectiva y el supuesto de que la desigualdad entre las culturas se explica por su tamaño, para sugerir una idea relacional de la identidad y una concepción de la desigualdad entre culturas basada en la relación dominación/subalternidad. Una crítica a la concepción del otro implícita en el enfoque multicultural que propugna por ir más allá de sus horizontes normativos, la tolerancia y la coexistencia, para construir el respeto, la convivencia, el diálogo y el aprendizaje mutuo entre culturas. Una crítica a la concepción formal de justicia que abandera el multiculturalismo, en favor de una justicia sustancial que vaya más allá del reconocimiento de derechos grupales para incluir cambios estructurales que ataquen las causas de la desigualdad y articulen la justicia cultural con la justicia social. Finalmente, una crítica a la concepción supremacista del multiculturalismo, que sostiene que las relaciones entre culturas se deben desarrollar en el marco liberal estableciendo a priori una desigualdad entre ellas". Cfr. CRUZ, Edwin (2014). "Multiculturalismo, interculturalismo y autonomía”. Estudios Sociales, No 43, pp. 243-269. Asimismo, véase: VillaVicenCio, Luis (2012). "Un diálogo intercultural más allá del multiculturalismo". Opinión Jurídica, No 22, pp. 31-44. 
no, lo interesante es que a pesar de las diferencias de enfoques entre las visiones normativas del fenómeno multicultural existe una intersección en sus planteamientos, que implican un gran cambio normativo y enormes desafíos para el sistema constitucional e institucional, los que podríamos resumir en los siguientes aspectos: 1) Se reconoce la importancia de la cultura grupal o particular en la construcción de la identidad de los individuos; 2) Se acepta la posibilidad de que los individuos de grupos culturales o étnicos tengan un reconocimiento expreso de sus particularidades de forma normativa, posibilitando la protección de estos frente a las injerencias de la cultura mayoritaria; 3) Se refuerza todo el aparato normativo e institucional antidiscriminatorio hacia los individuos de los grupos étnicos o culturales desaventajados ${ }^{16}$.

Así, en términos prácticos y normativos, la discusión gira en torno a las formas de tutela a las minorías nacionales o étnicas y los inmigrantes. Se da un salto en el hecho de que la justicia social pueda ser definida en términos de reglas que no hagan caso omiso de las diferencias, se acepta que puedan ser desiguales. De igual forma, se invierte la carga de la prueba, la que ya no corresponde a quienes defienden los derechos de las minorías, sino a quienes plantean que las reglas no deben hacer caso de las diferencias, debiendo probar que el status quo no crea injusticias para los grupos culturales o étnicos desaventajados.

Pese a la intersección de posturas señaladas, la gran diferencia teórica que existe entre el liberalismo (cultural) por un lado y el comunitarismo e interculturalismo por otro, se encuentra en el reconocimiento y conceptualización de los derechos de los grupos. Para los comunitaristas e interculturalistas los derechos de grupos o colectivos ${ }^{17}$ son fundamentales para la protección de los grupos étnicos y culturales. Sin embargo, para los liberales los derechos de los grupos son una categoría conceptual que no tendría cabida dentro del liberalismo ${ }^{18}$. De todas formas, hay que tener presente que existen autores liberales que plantean la compatibilidad de los derechos de los grupos con el liberalismo ${ }^{19}$.

\footnotetext{
${ }^{16}$ Para Kymlicka, existiría un consenso teórico en torno al liberalismo cultural, no sólo dentro de los liberales, sino que también en las otras perspectivas teóricas. Cfr. KYмLICKA (2001), pp. 59-71.

${ }_{17}$ Para Bhikhu Parekh, el concepto "derechos colectivos" es genérico y los derechos de los grupos son especies que pertenecen a ese género. Asimismo, realiza una distinción entre derechos colectivos derivados y primarios, basada en la forma o naturaleza de su adquisición. Cuando los individuos ponen en común sus derechos o los ceden a la colectividad, se habla de derechos colectivos derivados. Si los grupos adquieren derechos por lo que son y no de forma derivada, estaríamos en presencia de un derecho colectivo primario y que serían los que interesarían para el presente trabajo. Cfr. PAREKH, Bhikhu (2005). Repensando el multiculturalismo [Rethinking Multiculturalism]. Chaparro, Sandra (Trad.), Madrid: Istmo, p. 317.

${ }^{18} \mathrm{Al}$ respecto, véase: BARRY, Brian (2005). Culture and equality: an egalitarian critique of multiculturalism. Cambridge: Harvard University Press, pp. 61-103.

${ }^{19} \mathrm{Al}$ respecto, véase: Torbisco, Neus (2006). Group Rights as Human Rights. A Liberal Approach to Multiculturalism. Barcelona: Springer, 263 pp. Asimismo, revisando la posibilidad de conceptualizar derechos de grupo en el plano de la teoría del derecho, véase: Rodríguez AbASCAL, Luis (2002). "El debate sobre los derechos de grupo". En: Estado, Justicia y Derechos, Madrid: Alianza Editorial, pp. 409-434.
} 
Con estas breves pinceladas teóricas sobre el fenómeno multicultural, he buscado poner en contexto la discusión constitucional al respecto y señalar que, más allá del enfoque a utilizar, debido a lo incipiente del debate en Chile, puede resultar de gran utilidad comenzar con la intersección anotada, antes de decantarse por alguno de los enfoques señalados. En el próximo punto analizaré de forma particular, la recepción internacional y constitucional del fenómeno multicultural de fuente indígena. La principal normativa internacional y nacional en materia migratoria será revisada en el punto segundo, junto con el análisis normativo de la Constitución en la materia.

\section{Formas DE ACOMODACIÓN DE LA}

\section{MULTICULTURALIDAD EN LAS CONSTITUCIONES LATINOAMERICANAS}

Durante las últimas tres décadas, tanto en el derecho internacional, como en el plano constitucional, se ha producido un vertiginoso desarrollo de los derechos de los pueblos indígenas. En el ámbito internacional, se fue produciendo un cambio de enfoque, decidiéndose que para acomodar la diversidad cultural no bastaba con la protección de los derechos humanos por la vía individual ${ }^{20}$. El punto de inflexión se produce con la aprobación del Convenio No 169 sobre Pueblos Indígenas y Tribales en Países Independientes, de la Organización Internacional del Trabajo de 1989 (en adelante "Convenio No 169 de la OIT”). Éste es el primer instrumento internacional que se refiere a los "Pueblos Indígenas" como tal.

El Convenio No 169 de la OIT, "separó radical y definitivamente el tema indígena de la cuestión de las minorías, en la medida que los indígenas aparecen con derechos colectivos reconocidos en forma explícita, cuestión que no ocurre de la misma manera con las minorías". Esto es, a mi juicio, lo más importante del Convenio.

Avanzando en la protección de los derechos de los pueblos indígenas la Declaración de Naciones Unidas sobre los derechos de los pueblos indígenas, adoptada en septiembre de 2007 (en adelante "DPPI") reforzó las dimensiones colectivas de los derechos humanos de los pueblos indígenas. La declaración en los artículos $3^{\circ}$ y $4^{\circ}$ reconoce expresamente el derecho a la libre determinación, asociado al autogobierno y la autonomía, para resolver sus asuntos internos, disponer de medios para ello y elegir libremente su desarrollo económico, social y cultural.

En el mismo sentido, en el artículo $5^{\circ}$ de la DPPI se reconoce el derecho de los pueblos indígenas a "conservar y reforzar sus propias instituciones politicas, jurídicas, económicas, sociales y culturales, manteniendo a la vez su derecho a participar plenamente, si lo desean, en la vida política, económica, social y cultural

\footnotetext{
${ }^{20}$ Véase: Torbisco, Neus (2014). "Derechos indígenas: reconocimiento y desafíos para la democracia constitucional y para los derechos humanos". En: Autonomía individual frente a autonomía colectiva. Derechos en conflicto, Madrid: Marcial Pons, pp. 82-127.
} 
del Estado". Como se puede apreciar, hay un reconocimiento explícito al autogobierno y, por ende, a la dimensión colectiva de sus derechos. En los artículos $11,12,13,14,15,16$ y 17, se establece el derecho de los pueblos indígenas a lo que se ha denominado como "supervivencia cultural", con el deber por parte del Estado de adoptar medidas eficaces para asegurar su protección. El artículo 13 en su punto primero señala el derecho a la práctica de la cultura y en el punto segundo, el deber del Estado a asegurar dicho derecho, es decir, el derecho a la "supervivencia cultural".

En similares términos al del Convenio No 169 de la OIT, la DPPI reconoce derechos de autogobierno, de representación, de polietnicidad (especialmente de educación) y en general, se vela por un trato intercultural y de reconocimiento con el Estado que alberga en su seno pueblos indígenas ${ }^{21}$.

Como se ha podido apreciar, el derecho internacional para los pueblos indígenas se ha desarrollado ampliamente, tomando decisiones concretas por reconocer estatus a ellos, y estableciendo, entre otros aspectos, de forma expresa derechos de grupo a los pueblos indígenas ${ }^{22}$. Por su parte, los Estados que conforman América Latina no se han encontrado exentos del desarrollo internacional de los derechos de los pueblos indígenas. En su mayoría, han aprobado los Convenios señalados, suscrito las declaraciones mencionadas y han constitucionalizado los derechos de los pueblos indígenas ${ }^{23}$.

El valor que tiene el reconocimiento constitucional de la diversidad cultural de un país es un consenso tanto para quienes propugnan ideales liberales, comunitarios e interculturales. Por ello, me interesa identificar los principales "problemas" normativos que se han producido o esgrimido en torno al reconocimiento constitucional del multiculturalismo de fuente indígena, tomando en consideración que la mayoría de los países del continente durante los últimos 20 años han reconocido

${ }^{21}$ De forma similar, pero en razón de la realidad americana, en el año 1989 la Asamblea General de la OEA solicitó a la CIDH la preparación de un instrumento jurídico relativo a los derechos de las "poblaciones indígenas". Luego de un largo proceso de trabajo con organizaciones de la sociedad civil y grupos indígenas, la CIDH en 1997 aprobó el Proyecto de Declaración Americana sobre los Derechos de los Pueblos Indígenas. En marzo de 1997 la CIDH puso el proyecto de declaración a disposición de la Asamblea General de la OEA, el que no ha sido aprobado hasta la fecha. El proyecto de declaración es un instrumento internacional muy avanzado y que en gran parte de sus disposiciones ha sido recogido en la DPPI.

22 Además, los derechos de los grupos han sido expresamente reconocidos por el Sistema Interamericano de Protección de los Derechos Humanos. Al respecto, véase: Gajardo FalCón, Jaime (2014). "Derechos de los grupos en el Sistema Interamericano de Protección de los Derechos Humanos". En: Autonomía individual frente a autonomía colectiva. Derechos en conflicto, Madrid: Marcial Pons, pp. 145-171.

${ }^{23}$ Véase: Gargarella, Roberto (2013). "Nuevo constitucionalismo latinoamericano y derechos indígenas". En: Autonomía individual frente a autonomía colectiva. Derechos en conflicto, Madrid: Marcial Pons, pp. 129-143. La constitucionalización de los derechos indígenas, según Yrigoyen, ha tenido tres etapas: 1) El constitucionalismo multicultural (1982-1988); 2) El constitucionalismo pluricultural (1989-2005); 3$)$ El constitucionalismo plurinacional (2006-2009). Al respecto véase: YrigoYEN, Raquel (2011). "El horizonte del constitucionalismo pluralista: del multiculturalismo a la descolonización”. En: El derecho en América Latina: Un mapa para el pensamiento jurídico del siglo XXI, Buenos Aires: Siglo XXI, p. 140. 
constitucionalmente la diversidad cultural ${ }^{24}$. En ese sentido, seguiré en cuanto al fondo lo señalado por Miguel CARBONELL ${ }^{25}$ haciendo algunas variaciones de orden y de enfoque. Para ello, Carbonell ha planteado los siguientes "problemas": 1) Identificación del sujeto; 2) La tensión entre individuo y comunidad en los derechos indígenas; 3) Armonización entre derecho indígena y derecho nacional.

A estos puntos, agrego un aspecto que considero fundamental y tiene relación con el reconocimiento constitucional de la opción de vida (y desarrollo) que tengan los pueblos indígenas, y las colisiones que ello pueda originar con el modelo económico consagrado en la Constitución. Ello se abordará dentro de la tensión identificada con el número 2 del párrafo anterior, por cuanto ésta se produce en el ámbito institucional.

El primer aspecto que se analiza en el reconocimiento constitucional de los derechos indígenas dice relación con las supuestas complejidades para identificar el sujeto y el objeto sobre el cual se asignarán derechos y obligaciones. Las preguntas que surgen son: ¿Cómo determinar al sujeto protegido o pueblo indígena? ¿Cuál es el bien cultural protegido? ¿Qué es una cultura?

Las anteriores preguntas giran en torno a lo mismo: ¿cómo identificar una cultura indígena dentro de una sociedad mayoritariamente mestiza? Tal como anota CARBOnELl, muchas de estas preguntas surgen al inicio del debate sobre la constitucionalización de los derechos indígenas, con la intención de cerrar el debate ${ }^{26}$, buscando como excusa la imposibilidad de determinación del sujeto. En el punto siguiente, analizaré con mayor detención esta objeción, cuando se revise este aspecto

\footnotetext{
${ }^{24}$ Con sus diferencias, los países de América mayoritariamente han reconocido constitucionalmente su diversidad cultural, siguiendo modelos para ello, teniendo Constituciones políticas que reconocen todos o algunos de los siguientes puntos: 1) A los pueblos indígenas como tales; 2) La diversidad cultural; 3) La libre determinación de los pueblos; 4) Derechos de participación política; 5) Derechos de tierras, territorios y recursos naturales; 6) Lenguas indígenas; 7) Educación intercultural bilingüe; 8) Derecho Consuetudinario Indígena. La Constitución del Estado Plurinacional de Bolivia del año 2009, Colombia (1991), Ecuador (2008), México (2001) y Nicaragua (1986), las más avanzadas en la materia, ya que reconocen todos los puntos recién señalados. Así, además en las Constituciones de Argentina (1994), Brasil (1988), Costa Rica (1999), El Salvador (1992), Guatemala (1992), Honduras (1982), Paraguay (1992), Perú (1993) y Venezuela (1999), se reconoce constitucionalmente (con sus diferencias) la diversidad cultural, integrando uno o más de los puntos precitados. Cfr. Aguilar, Gonzalo; Lafosse, Sandra; Rojas, Hugo y Steward, Rebecca (2010). "The Constitutional Recognition of Indigenous Peoples in Latin America”. Pace International Law Review Online Companion, No 2, pp. 44-104. Asimismo véase: Gargarella, Roberto (2013). Latin American Constitutionalism 1810-2010. Oxford: Oxford University Press, pp. 172-195. Sobre el desarrollo constitucional de los países de América Latina en materia indígena durante los siglos XIX y XX, véase: Clavero, Bartolomé (2006). “Derechos Indígenas y Constituciones Latinoamericanas”. En: Pueblos indígenas y derechos humanos. Bilbao: Instituto de Derechos Humanos, Universidad de Deusto, pp. 313-338.

25 Cfr. Carbonell, Miguel (2004). “Constitucionalismo y Multiculturalismo”. Derecho y cultura, Año 10, No 13, pp. 21-80.

${ }^{26} \mathrm{Al}$ respecto apunta Carbonell: "Se trata de preguntas válidas, pero a veces tenían más la intención de cerrar el debate que de refinarlo. En cualquier caso, una parte de las mismas preguntas es la primera de las dificultades a las que tuvo que enfrentar el proceso de constitucionalización de los derechos indígenas en América Latina”. Carbonell (2004), p. 47.
} 
como una de las dificultades de los derechos de los grupos. Sin embargo, comparto lo señalado por Carbonell, en el sentido que el Convenio 169 de la OIT sirve como punto de partida para la identificación clara del sujeto. En su artículo $1^{27}$, el convenio da una definición del sujeto, que se ha aplicado en la gran mayoría de los países de la América Latina, con operatividad práctica y no sólo teórica ${ }^{28}$.

Como segundo aspecto complejo, se ha señalado la tensión existente entre individuo y comunidad en el derecho indígena. A mi juicio, este es el aspecto más importante y complicado para la teoría del derecho constitucional. Las primeras legislaciones indígenas buscaron resolver esta tensión, atribuyendo derecho al indígena $^{29}$, y no a su "pueblo", como comunidad. Sin embargo, el Estado unitario liberal no da las respuestas adecuadas a "pueblos" que tienen una concepción del mundo basada en lo "colectivo" más que en lo "individual”. Para que la teoría del derecho pueda abordar seriamente esta cuestión, se debe analizar si los derechos de los grupos son compatibles o no dentro de un Estado democrático de derecho ${ }^{30}$.

En tercer lugar, en cuanto a la armonización del derecho indígena con el nacional, el tema que se plantea aquí es si el Estado reconoce o no el pluralismo jurídico. CARBOnell anota que en la mayoría de los Estados de América Latina la aspiración del pluralismo jurídico por parte de los pueblos indígenas ha sido reconocida en mayor o menor medida ${ }^{31}$. Sin embargo, ello no implica que se hubieran resuelto los problemas de armonización jurídica que trae consigo la coexistencia de dos ordenamientos jurídicos tan diversos dentro del Estado ${ }^{32}$.

CARBOnell apunta que estas tensiones se pueden dar en dos dimensiones: una individual y otra organizativa o institucional. En el plano individual, según CARBONELL ${ }^{33}$, los problemas de armonización dicen relación con la tensión que se

\footnotetext{
${ }^{27}$ En el punto primero del artículo $1^{\circ}$, para atribuir la condición de "pueblo indígena" se toma en consideración aspectos geográficos, históricos, culturales y sociales. Luego ello se integra con el punto segundo, que da valor a la "autoidentificación".

${ }^{28}$ Sobre los criterios que se tienen en cuenta por los organismos internacionales para identificar un "pueblo indígena o tribal", véase: Comisión Interamericana de Derechos Humanos (2009). Derechos de los Pueblos Indigenas y Tribales sobre sus Tierras Ancestrales y Recursos Naturales. OEA/Ser. L/V/II. Doc. 56/09, pp. 9-13.

${ }^{29}$ Un ejemplo es la Ley chilena No 19.253, que establece normas sobre protección, fomento y desarrollo de los Indígenas, y crea la Corporación Nacional de Desarrollo Indígena, Diario Oficial, 5 de octubre de 1993. Dicha norma, en su artículo $1^{\circ}$ establece que el sujeto protegido es el "indígena", no el "pueblo indígena”.

${ }^{30} \mathrm{Al}$ respecto véase el reciente aporte de TORBISCO (2014), pp. 82-127.

31 Carbonell (2004), p. 53.

32 Escéptica se muestra en éste punto Marian Ahumada, señalando que la coexistencia de ambos derechos junto con ser compleja, presenta serios problemas de legitimidad democrática. Véase: AHUMADA, Marian (2008). "Derecho Indígena y Constitucionalismo Democrático: una mirada crítica”. En: Derechos, costumbres y jurisdicciones indigenas en la América Latina contemporánea. Madrid: Centro de Estudios Políticos y Constitucionales, p. 235.

33 Carbonell (2004), pp. 54-55.
} 
produce entre los Derechos Humanos y Fundamentales y los "usos y costumbres" de los pueblos indígenas. Un mayor respeto por los derechos humanos implica menor aceptación de los usos y costumbres; ergo, mayor laxitud con los derechos humanos, implica mayor aplicación de "usos y costumbres".

Comparto con Carbonell el punto central del análisis: la tensión es entre derechos humanos y "usos y costumbres". Sin embargo, creo que la pregunta debe ser en cuanto al entendimiento de los derechos humanos, en un marco multicultural. Que los derechos humanos o fundamentales sean límite aceptable para la aplicación del pluralismo jurídico me parece inobjetable, pero el cómo se entienden e interpretan los derechos humanos considero que es un tema en desarrollo ${ }^{34}$. Ello implica que el centro sea la integración de visiones, en el plano discursivo y, por ende, en la interpretación del significado de los derechos humanos. Si los derechos humanos se entienden sólo con un prisma occidental, la tensión tiende a volverse irresoluble e irreconciliable. La pregunta que habría que resolver en el plano de la filosofía del derecho, es si: ¿Es posible la multiculturalización de los derechos humanos? Responder a la pregunta excede a los objetivos del presente trabajo, pero sirve para señalar que es un tema abierto en la discusión filosófica jurídica ${ }^{35}$.

La segunda dimensión en este punto es la tensión que se produce en el plano organizativo o institucional. Aquí, la problemática surge por el autogobierno indígena y su armonización con las instituciones nacionales, surgiendo problemas en cuanto a las políticas educacionales, de desarrollo, ambientales, e incluso de tipo electoral ${ }^{36}$. Para la gestión de este tipo de complejidades, CARBONELL anota un aspecto que debe tenerse en cuenta (también en el caso de los inmigrantes), y que comparto absolutamente. Señala que:

"Los grupos que reivindican a la vez cuestiones redistributivas y de reconocimiento son llamados por Fraser 'comunidades bivalentes', que se diferencian del resto en virtud tanto de la estructura socio-económica como de la estructura de la valoración cultural. En casi todos los países de América Latina, los indígenas son una comunidad

\footnotetext{
${ }^{34}$ Hay que tener presente que para llevar un debate serio, no se pueden idealizar posiciones, ni extremar los ejemplos. No comparto que se señale, por ejemplo, que las prácticas de los pueblos indígenas son en su mayoría contrarias a los derechos humanos, justificándose ello con ejemplos puntuales y muy repetidos. De igual forma, tampoco comparto la idealización de los "pueblos indígenas". El debate debe buscar la integración cultural, no buscar ejemplificar "superioridades culturales", ya sea de cosmovisión occidental o indígena.

${ }^{35} \mathrm{Al}$ respecto, véase: ETcheverRía, Xabier (2006). "La tradición de los derechos humanos y los pueblos indígenas: una interpelación mutua". En: Pueblos indígenas y derechos humanos, Instituto de Derechos Humanos, Universidad de Deusto, Bilbao: España, p. 77. Asimismo, sobre la interpretación contextualizada de los Derechos Humanos en marcos multiculturales, véase: Álvarez, Silvina (2014). "Los derechos humanos como valores plurales. Multiculturalismo, cosmopolitismo y conflictos". En: Entre Estado y Cosmópolis, Madrid: Editorial Trotta, pp. 179-212.

${ }^{36}$ Para Gargarella, es necesario no sólo poner atención en el reconocimiento de derechos, sino que también en la distribución de poderes, en los aspectos institucionales y orgánicos de la constitución, para promover la inclusión social. Véase: GARGarella (2013), p. 184.
} 
'bivalente', pues padecen discriminaciones por falta de reconocimiento, como de tipo socio-económico".

Tomando en consideración lo anotado por CARBONELL, es relevante que las políticas de reconocimiento tomen en cuenta: la interdependencia del reconocimientoredistribución, en la formulación realizada por FRASER ${ }^{37}$, o el reconocimiento que implica justicia material, según el esquema de $\mathrm{HONNETH}^{38}$. Ya que si no lo hacen en su formulación, se corre el riesgo de ser un reconocimiento de tipo "simbólico"39.

\section{PRincipales aspectos CRÍticos de la \\ CONSTITUCiÓn Política 1980-2005 y LA DiVERSIDAD CULTURAL}

\subsection{En materia indigena}

La política indígena elaborada por la dictadura militar y su legislación, que ha sido catalogada como destructura de la comunidad ${ }^{40}$, vieron en la elaboración y posterior aprobación de la Constitución Política de 1980 su fundamentación normativa e ideológica. La Constitución de 1980 tiene una coherencia en sus ideas políticas $^{41}$, que permiten su sistematización y, por ende, su apreciación ideológica sin mayores inconvenientes teóricos.

En la Constitución Política de 1980, se busca (con éxito) dar expresión normativa a un cuarteto valorativo ${ }^{42}$ representado por los ideales de libertad, seguridad, progreso y justicia, que constituirían una forma de vida intrínseca de la persona y que, por tanto, la Constitución debiera proteger de sus posibles amenazas, y

37 Cfr. Fraser, Nancy (2006). "La justicia social en la era de la política de la identidad: Redistribución, reconocimiento y participación”. En: ¿̨edistribución o reconocimiento? [Umverteilungo der Anerkennung?]. Manzano, Pablo (Trad.) Madrid: Morata,pp. 71-88.

38 Cfr. Honneth, Axel (2006). “Redistribución como reconocimiento: Respuesta a Nancy Fraser”. En: ¿Redistribución o reconocimiento? [Umverteilung oder Anerkennung?]. ManZano, Pablo (Trad.), Madrid: Morata, pp. 89-148.

${ }^{39}$ Cfr. Yrigoren (2011), p. 143.

40 El proceso de liquidación de las comunidades mapuche, la dictadura militar lo realizó mediante la aplicación del Decreto Ley No 2.568 de 1979, el que tenía por objetivos: 1) Promover el pleno acceso a la propiedad individual, mediante la entrega de títulos de propiedad a los mapuche y otros pueblos indígenas; 2) Lograr una asimilación total de los pueblos indígenas en la sociedad chilena; 3) Desarrollar una política agresiva para erradicar la "pobreza" de las comunidades mapuche y otros pueblos indígenas.

${ }^{41}$ Justamente la coherencia del ideal político establecido en la Constitución de 1980, permiten a Renato Cristi (junto a otros aspectos) sistematizar el pensamiento político de Jaime Guzmán, quien ha sido reconocido como el principal ideólogo de la Constitución. “(...) en un modo análogo al de los Founding Fathers de la Constitución americana, sus ideas políticas, particularmente en el ámbito del derecho constitucional, son coherentes y admiten de sistematización”. Cfr. CRISTI, Renato (2011). El pensamiento político de Jaime Guzmán. Santiago: Lom ediciones, 2a edición, p. 17.

${ }^{42}$ En un sentido similar, para el profesor Francisco Zúñiga, la Constitución de 1980 cristaliza, en su parte dogmática, los componentes ideológicos de una refundación autoritaria del capitalismo, los que serían: originariamente autoritarios, neoliberales, iusnaturalistas y lejanamente corporativistas. Cfr. ZúNigA, Francisco (2007). "Vieja-Nueva Constitución". Estudios Constitucionales, No 1, pp. 349-370. 
en particular de las decisiones de la mayoría, creando para ello sistemas contra mayoritarios al interior de la Constitución ${ }^{43}$.

Para los ideólogos de la Constitución de 1980, el ideal de libertad representaba una idea prepolítica, un valor absoluto y una condición para la realización del resto de los valores morales que les interesa proteger. La noción de libertad aparece ligada de manera irresoluble a la propiedad privada, los derechos individuales, la libertad de asociación y de empresa. Se busca una individualidad privada libre de cualquier interferencia, con la menor intervención estatal posible y con una Constitución Política que blinde al máximo dichos ideales, neutralizando la actuación del pueblo mediante una gran gama de mecanismos constitucionales ${ }^{44}$.

Para el profesor Francisco Zúniga, la Constitución de 1980 es:

“(...) una refundación autoritaria del capitalismo, con nítido sello neoliberal expresada en la fórmula del Estado subsidiario (mínimo); amplia recepción de derechos civiles de contenido patrimonial revestidos de una protección judicial extraordinaria-urgente en el proceso de amparo de derechos ante tribunales superiores de justicia; 'autonomías constitucionales' como dispositivos contramayoritarios y enderezadas a defender o custodiar el 'orden constitucional' (Tribunal Constitucional y Banco Central); y 'enclaves autoritarios' subsistentes como la legislación de 'supermayorías' o de quórum especial para dotar de estabilidad el desarrollo de ciertos institutos de la parte dogmática de la Constitución (previsión, salud, educación, enseñanza, limitaciones a la libertad de adquirir bienes, propiedad minera, Estado empresario y amparo económico, entre otras) o de la parte orgánica de la Constitución (bases de la Administración del Estado, Congreso Nacional, Fuerzas Armadas y de Orden, Tribunal Constitucional, Banco Central, Contraloría General de la República y Gobierno y Administración interior)”45.

Esta búsqueda de protección máxima de la "libertad", entendida en su vertiente neoliberal ${ }^{46}$, llevó a los redactores de la Constitución de 1980 a la utilización del

\footnotetext{
43 Para Jaime Guzmán, la forma de vida intrínseca es mediada por la democracia, la que considera una forma de gobierno que tiene un valor solo instrumental. Así señala Jaime Guzmán: "La democracia es una forma de gobierno, y como tal solo un medio -y ni siquiera, el único o el más adecuado en toda circunstancia- para favorecer la libertad, que en cambio integra la forma de vida hacia la cual todo sistema político humanista debe tender como fin u objetivo. Dicha forma de vida incluye además la seguridad y el progreso, tanto espiritual como material, y dentro de esto, tanto económico como social”. Cfr. CRISTi (2011), p. 23. Siguiendo lo expuesto por Cristi, disiento de lo señalado por Humberto Nogueira, en el sentido de que el objetivo central del régimen militar era la estructuración de una democracia autoritaria y protegida. Ello no es el objetivo central, sino el medio que utilizan los ideólogos de la Constitución, para garantizar los valores e ideales que buscan proteger de las decisiones de la mayoría. Cfr. Nogueira, Humberto (2009). "La evolución político-constitucional de Chile 1976-2005”. En: La evolución político-constitucional de América del Sur 1976-2005. Santiago: Librotecnia, pp. 338-393.

${ }^{44} \mathrm{Al}$ respecto, véase: Atria (2013a), pp. 31-85.

45 ZúNítga, Francisco (2011). "Nueva Constitución y Constitucionalismo en el Bicentenario". En: XLI jornadas chilenas de Derecho Público. Santiago: Universidad de Chile, Facultad de Derecho, pp. 6-7.

46 Un excelente trabajo sobre el significado y alcance del "neoliberalismo" y en particular de su versión chilena, véase: Atria, Fernando (2013b). Veinte años después. Neoliberalismo con rostro humano. Santiago: Catalonia, pp. 33-54.
} 
principio de subsidiariedad ${ }^{47}$ en la parte dogmática de la Constitución, en particular en el primer artículo y capítulo, de la misma, que se denomina: "Bases de la Institucionalidad".

El principio de subsidiariedad busca ordenar la relación entre persona, grupos intermedios (sociedad civil) y Estado. La organización es de carácter jerárquico y viene dada por la "naturaleza de las cosas", lo que implica una visión de tipo iusnaturalista.

Junto a lo anterior, impone la obligación de que el Estado respete el "orden natural de las cosas", el que sería profundamente individualista, con miras a evitar toda forma de colectivismo.

Así, la función principal del Estado, es la de "dirigir, vigilar, reprimir, según los casos y la necesidad lo exigen", el orden natural de las cosas, protegiendo a la familia, los individuos y los grupos intermedios.

Con la plasmación del principio de subsidiariedad, en el sentido católico, en el artículo $1^{\mathrm{o}}$ de la Constitución Política de la República, los redactores de la Constitución buscaron establecer un modelo de sociedad, basado en la intervención mínima del Estado en la economía y en la reducción de su labor a la del Estado policial del liberalismo clásico ${ }^{48}$.

${ }^{47}$ El Principio de subsidiariedad fue creado por la Iglesia Católica y tiene su origen en documentos pontificios. En ese sentido la encíclica Quadragesimo Anno de Pío XI señala que:"Conviene, por consiguiente, que la autoridad pública suprema deje a las asociaciones inferiores tratar por sí mismas aquellos asuntos y negocios que ellas puedan resolver, de menor importancia, en los cuales por lo demás perdería mucho tiempo o le serían de grandísimo impedimento para cumplir con mayor libertad, firmeza y eficacia cuanto a ella sola corresponde, pues de su exclusiva competencia, a saber: dirigir, vigilar, estimular, reprimir, según los casos y la necesidad lo exigen. Por lo tanto, tengan bien entendido los gobernantes que mientras más vigorosamente reine el orden jerárquico entre las diversas asociaciones, quedando en pie y a salvo este principio de la función subsidiaria del Estado, tanto más firme será no sólo la autoridad sino también la eficiencia social, y tanto más feliz y más próspera la condición del Estado”. En: Pío XI (1953). Quadragesimo Anno. Santiago: Talleres gráficos Pía Sociedad San Pablo. En: Ruiz-Tagle, Pablo (2000). "Principios Constitucionales del Estado Empresario". Revista de Derecho Público, No 62, pp. 47-59. Recurro a la versión católica del principio de subsidiariedad, porque fue la utilizada por la Comisión de Estudios de la Nueva Constitución, es decir, el artículo $1^{\circ}$ de la Constitución Política de la República de Chile se encuentra inspirado en el principio de subsidiariedad en su entendimiento católico.

48 Intentando construir una concepción doctrinaria más amplia de la Constitución y buscando limitar la importancia del principio rector de subsidiariedad que tiene la Constitución Chilena, el profesor Ruiz-Tagle señala que: "Ciertamente, puede aceptarse que la carta fundamental chilena es el producto de una transacción de diversas ideas políticas y constitucionales, entre las cuales se encuentran algunas que representan una tradición de orientación católica y raíz iusnaturalista cristiana. Sin embargo, esta constatación no debe hacernos olvidar que también se puede vincular la constitución chilena a la tradición política liberal y a una serie de propuestas e ideas que son propias de la tradición social demócrata o socialista. Si se acepta esta tesis de la transacción de diversas tradiciones, como una base plural sobre la cual se construye la constitución política chilena, se debe atribuir importancia limitada al principio de subsidiariedad. Desde esta perspectiva, el principio de subsidiariedad se considera como relevante para los que hacen suya la tradición constitucional iusnaturalista, sin perjuicio que incluso en ese caso, la subsidiariedad no alcanza el nivel de un principio de derecho constitucional sino una forma ideológica variable, sin un contenido claro que intenta servir de guía para ordenar la relación entre las personas y el Estado". Cfr. Ruiz-TAgLE (2000), pp. 47-59. En un sentido similar, Jaime Bassa, tiene una propuesta interpretativa y doctrinaria sobre la 
Al principio de subsidiariedad se unen la idea de un Estado-Nación, monocultural y con unidad territorial. Donde la ciudadanía se encuentra ligada a la nacionalidad y la avecindad en el país. De ello dan cuenta el artículo 2o (emblemas nacionales), $3^{\circ}$ (unidad territorial), 5º (soberanía nacional) y el Capítulo II, sobre nacionalidad y ciudadanía.

La Constitución de 1980 busca perpetuar una visión de mundo, en la cual no se integra la perspectiva de los pueblos indígenas ${ }^{49}$. No establece reconocimiento constitucional a los pueblos indígenas, ni derechos diferenciados. Tampoco reconoce valores o principios que permitan entender la diversidad cultural. El criterio utilizado por los ideólogos de la Constitución de 1980, al respecto, consiste en preceptuar el principio de igualdad ante la ley para todos los habitantes de la República, sin hacer distinción de ningún tipo.

Junto a lo anterior, es importante tener en cuenta que en la Constitución de 1980 se constitucionalizó el derecho de propiedad y se le dio un carácter prácticamente absoluto. En el texto original de la Constitución de 1980, a diferencia de la Constitución de 1925, no se establecía la función social de la propiedad.

La Constitución de 1980 regula en forma lata tanto el derecho de propiedad (artículo 19, No 24), la libertad para adquirir el dominio (artículo 19, No 23) y la protege con la no afectación de las garantías constitucionales en su esencia (artículo 19, No 26) y el recurso de protección (artículo 20).

Para los ideólogos de la Constitución de 1980, “(...) la noción de propiedad está estrechamente unida a la noción de libertad. El derecho de propiedad es una

Constitución de 1980, en el sentido de que esta debe ser re-interpretada en sus fundamentos y significados desde la Teoría Constitucional contemporánea y a partir de 1990 momento desde el cual sólo cabría hablar de Constitución en sentido estricto. Cfr. BASSA, Jaime (2008). El Estado Constitucional de Derecho. Santiago: LexisNexis, 220 pp. Considero que el esfuerzo de ambos académicos, en términos intelectuales-doctrinarios, para limitar el peso del principio de subsidiariedad es importante y merece ser rescatado. Sin embargo, lamentablemente, dicho principio ha sido en la práctica una guía ideológica que ordena la relación de las personas y el estado, siendo además en forma reiterada usado por la jurisprudencia nacional, en todos sus niveles, como fundamento de sentencias. Por ello, cobra mucho más sentido buscar una nueva Constitución o una reforma importante en dichas materias.

49 Manuel Núñez, señala que el no reconocimiento de los pueblos indígenas en la Constitución de 1980, se debe a: “(...) la completa ignorancia que los redactores de la Constitución vigente demostraron tener hacia la cuestión indígena, lo que supuso producir un texto en el que difícilmente tenían cabida (bajo el concepto de 'grupo intermedio', por ejemplo) los derechos de las comunidades indígenas al modo como se entienden hoy en día. Por el contrario, los principios constitucionales de la 'unidad estatal' (art. $3^{\circ}$ Const. Pol.) y 'unidad de la soberanía' (art. 5º Const. Pol.), como asimismo las concepciones predominantemente europeas sobre el contenido de los derechos vinculados a la religión o a la propiedad, conspiran en contra de una visión pluralista de aquella comunidad política que se construye a partir del texto constitucional". Cfr. NúñEZ, Manuel (2010). "Invitación al estudio del Derecho y los derechos de los pueblos indígenas en el Chile republicano". En: Normativa nacional e internacional sobre pueblos indígenas. Santiago: Librotecnia, pp.15-16. Sólo difiero con el autor precitado, en el hecho de que el no reconocimiento de los pueblos indígenas no se debe a ignorancia, quizás a desprecio, pero fundamentalmente a una concepción del mundo, con valores sólo occidentales, donde el ideario de los pueblos indígenas no tiene cabida alguna. 
aplicación de lo que significa ser persona: es la realización de la libertad personal" ${ }^{50}$. Así, proteger al máximo el derecho de propiedad en su sentido más absoluto y prepolítico, se vuelve una de las principales inspiraciones en la construcción normativa de la Constitución de 1980.

Todo lo anterior da sentido a la legislación liquidadora de la comunidad indígena dictada por la dictadura militar y tiene por objeto principal realizar una verdadera restauración capitalista de corte neoliberal en Chile. Dicha transformación, entre otras cosas, busca terminar con la propiedad colectiva de las tierras indígenas y asimilar a todos los habitantes del país en una cultura, anclada en los valores ya señalados. Como señala Vicente CABEDO al respecto: "Se trataba de integrar al indígena en la economía neoliberal impulsada por el régimen, siendo la propiedad privada individual un auténtico instrumento de aculturación de estos pueblos indígenas, de pérdida de su identidad" 51 .

La legislación dictada en Chile sobre pueblos indígenas e inmigración, desde la década de los 90 y las reformas constitucionales realizadas en el año 2005, han atenuado la legislación dictatorial y los impactos de la Constitución de 1980 sobre los pueblos indígenas.

El cuerpo normativo fundamental en materia indígena es la Ley No 19.253 de 1993. La Ley Indígena constituye un avance importante para los pueblos indígenas y su reconocimiento. Los aspectos de la Ley Indígena que se pueden considerar como un progreso en la materia son relativas a: 1) Reconocimiento cultural; 2) Protección; 3) Incipientes derechos de supervivencia cultural; 4) Aplicación mínima del derecho consuetudinario indígena.

En lo relativo al reconocimiento cultural, en la Ley se reconoce a los indígenas (artículo $1^{\circ}$ ) y se establece el deber del Estado y la sociedad en general, de respetar, proteger y promover el desarrollo de sus culturas, familias y comunidades. Importante en este punto es que la Ley Indígena incorpora el criterio de autoidentificación. Además el Estado reconoce a las principales etnias de Chile y valora su existencia por ser parte esencial de las raíces de la Nación chilena, así como su integridad y desarrollo, de acuerdo a sus costumbres y valores.

El Estado, en el artículo $9^{\circ}$ de la Ley Indígena, reconoce a las comunidades indígenas, y en los artículos 10 y 11 regula las modalidades para la formación de ellas, así como el registro público de las mismas.

Siguiendo en este plano, el Estado, en el Título II de la Ley Indígena, reconoce la importancia de la tierra para la identidad del indígena y entiende por tales aquellas que las personas o comunidades ocupan actualmente en propiedad o posesión, ya sea provenientes de títulos reconocidos por el Estado desde 1823 hasta la fecha y

\footnotetext{
${ }^{50}$ CRISTI (2011), p. 79.

51 Cabedo, Vicente (2004). Constitucionalismo y Derecho Indígena en América Latina. Valencia: Universidad Politécnica de Valencia, p. 266.
} 
hacia el futuro, así como aquellas que han ocupado históricamente siempre que sus derechos se encuentren en el Registro que crea esta ley.

En el plano de protección de los indígenas, la Ley establece mecanismos para el resguardo de las tierras indígenas y se crea un Fondo de Desarrollo Indígena (Título III de la Ley), con el fin de adquirir tierras para personas indígenas y sus comunidades. Esto es importante, ya que la usurpación de las tierras indígenas, la falta de protección legal y la división de sus comunidades causaron durante los siglos XIX y XX un gran daño a los pueblos indígenas. Además, crea la Corporación Nacional de Desarrollo Indígena, organismo público que tiene por misión, según el artículo 39 la de: "promover, coordinar y ejecutar, en su caso, la acción del Estado en favor del desarrollo integral de las personas y comunidades indigenas, especialmente en lo económico, social y cultural y de impulsar su participación en la vida nacional'.

La Ley Indígena tiene incipientes derechos que tienden a la supervivencia cultural de las comunidades, éstos son principalmente aquellos que buscan: "El reconocimiento, respeto y protección de las culturas e idiomas indígenas, el establecimiento de un delito destinado a evitar la discriminación de los indígenas por su origen o cultura, la creación de un sistema educacional bilingüe con el objeto de preparar a los educandos indígenas para desenvolverse en forma adecuada tanto en su sociedad de origen como en la sociedad global, así como un programa de becas para los estudiantes indígenas" 52 .

En la Ley Indígena, se establece un mínimo reconocimiento al derecho consuetudinario indígena. En el artículo 54 se señala que: "La costumbre hecha valer en juicio entre indígenas pertenecientes a una misma etnia, constituirá derecho, siempre que no sea incompatible con la Constitución Política de la República. En lo penal se la considerará cuando ello pudiere servir como antecedente para la aplicación de una eximente o atenuante de responsabilidad".

En materia de justicia, se reconoce, además, un procedimiento especial para el trámite de los juicios sobre tierras en que se encuentre vinculado un indígena. Ello está regulado en los artículos 55 a 59 de la Ley Indígena.

Para José AYLWIN ${ }^{53}$, las principales limitaciones de la Ley Indígena, en relación a las tendencias actuales del derecho comparado sobre la materia, son tres. Primero, que no se reconoce a los indígenas como pueblos ${ }^{54}$. Ello implica negarles el derecho

\footnotetext{
52 AylWin, José (2000). Pueblos Indígenas de Chile: antecedentes históricos y situación actual. Disponible en: $<$ http://www.estudiosindigenas.cl/centro-de-documentacion> [Consulta: 12 abril 2013], p. 14.

53 Aylwin (2000), p. 15.

${ }^{54} \mathrm{Al}$ respecto Guillaume Boccara e Ingrid Seguel-Boccara señalan que: “(...) al no reconocer la existencia de 'pueblos indígenas', la ley se ubica en una posición bastante conservadora respecto de las normativas internacionales vigentes. (...) Notemos que el hecho de hablar de 'etnia' y no de 'pueblo', no solamente remite a un problema jurídico. Tiene que ver también con las luchas de clasificación que se ubican en la base de la reproducción del orden legítimo y dominante. Así, calificar a los indígenas de 'etnias' es hacerlos
} 
a la autodeterminación y autogobierno de los pueblos indígenas, el que ya ha sido reconocido en los convenios internacionales sobre la materia, y en la mayoría de las legislaciones comparadas. Es importante mencionar que el proyecto de Ley Indígena del ejecutivo, en su artículo $1^{\circ}$, hablaba de "pueblos" y no de "etnias", el que fue modificado durante su tramitación legislativa.

En segundo lugar, están las limitaciones realizadas por el Congreso a las áreas de desarrollo indígena, las que contemplaban mayores grados de autogestión para sus comunidades.

En tercer lugar, la eliminación del proyecto de ley del capítulo referido a los jueces de paz indígenas, "a través del cual se pretendía dar reconocimiento a las formas de resolución de conflictos menores aún subsistentes en las comunidades de modo de dar cabida al derecho propio o consuetudinario indígena" ${ }^{5}$.

A las críticas señaladas, Guillaume Boccara e Ingrid SEGUEL-BOCCARA ${ }^{56}$ plantean cuatro más que considero relevantes. La primera apunta a que la Ley Indígena debió reconocer los tratados firmados entre las naciones indígenas y la Corona Española. En segundo lugar, el no reconocimiento del pluralismo jurídico y el mínimo valor que se le da en la aplicación del derecho a la costumbre indígena ${ }^{57}$. Como tercer punto, el hecho de que la educación bilingüe es determinada por el Estado de forma unilateral. Y como cuarto aspecto, expresan que el fenómeno de población indígena urbana no es considerado por la ley.

Una última crítica que me parece relevante dice relación con el hecho de que en la Ley Indígena existen contradicciones en la forma en que se regulan instituciones y el entendimiento que tienen de ellas las comunidades indígenas. Un ejemplo de ello sería el caso de la propiedad comunitaria.

Finalmente, durante los últimos años, y por la influencia de las organizaciones indígenas, la presión de los organismos internacionales y la evolución del derecho internacional en la materia, la variable indígena ha permeado la actividad legislativa nacional, incorporándose la diversidad cultural en diversas disposiciones legales.

Por ejemplo en: 1) La Ley No 19.947 de 2004, nueva Ley de Matrimonio Civil, señala en su artículo 13 que: "Las personas pertenecientes a una etnia indigena, según el artículo 2 de la Ley $N^{\circ} 19.253$, podrán solicitar que la manifestación, la información para el matrimonio y la celebración de éste se efectúen en su lengua materna"; 2) La Ley No 20.246 de 2008, que crea el espacio costero marítimo de

existir en tanto que 'etnias', es decir como agrupaciones políticas pre-estatales, pre-modernas. Por lo tanto es reafimar de manera sutil que su identidad es pre-nacional". Cfr. BocCara, Guillaume y SEguel-Boccara, Ingrid (1999). "Políticas Indígenas en Chile (siglos XIX y XX). De la asimilación al pluralismo". Revista de Indias, No 217, pp. 741-774.

55 AYLWin (2000), p. 15.

56 Cfr. Boccara y Seguel-Boccara (1999), pp. 772-773.

57 Cfr. Cabedo (2004), pp. 268-270. 
los pueblos originarios, denominada Ley Lafkenche ${ }^{58}$. En el cuerpo normativo, se utiliza por primera vez en el ordenamiento jurídico chileno el término de "pueblos originarios" y alude al uso consuetudinario del territorio; 3) La Ley No 20.370 de 2009, Ley General de Educación, establece en su artículo 4º, inciso 7o , que: "es deber del Estado promover políticas educacionales que reconozcan y fortalezcan las culturas originarias". Le corresponde al Consejo Nacional de Educación, en todas las modalidades de educación escolar, según el artículo 52, letra b, “aprobar o formular observaciones a las adecuaciones curriculares para poblaciones especificas, incluidas, entre otras, los pueblos originarios y los talentos". En materia de supervivencia del idioma de los pueblos indígenas, el artículo 28 promueve como objetivo la enseñanza de las lenguas indígenas en los establecimientos que presenten un alto porcentaje de alumnos; 4) La Ley No 24.417 de 2010, que creó la nueva institucionalidad ambiental, modificó el artículo 4o de la Ley No 19.300, sobre Bases del Medio Ambiente, agregando el siguiente párrafo: "Los órganos del Estado, en el ejercicio de sus competencias ambientales y en la aplicación de los instrumentos de gestión ambiental, deberán propender por la adecuada conservación, desarrollo y fortalecimiento de la identidad, idiomas, instituciones y tradiciones sociales y culturales de los pueblos, comunidades y personas indígenas, de conformidad a lo señalado en la ley y en los convenios internacionales ratificados por Chile y que se encuentren vigentes". Además el artículo 11 de la ley, con el artículo 9o del Reglamento de la misma, han venido a conformar lo que se ha denominado como la "variable antropológica" 59 , que busca incorporar al proceso de evaluación ambiental los derechos de los pueblos indígenas.

Como señala Manuel NúNEZ: "El resto de la normativa legal dictada después de la Ley núm. 19.253 se refiere a asuntos marginales, tales como el uso del espectro radioeléctrico para la radiodifusión comunitaria (Ley núm. 20.433, D. Oficial de 4 de mayo de 2010, art. 40), el fomento para la recuperación del bosque nativo por pequeños propietarios forestales (Ley núm. 20.283, D. Oficial de 30 de julio de 2007), el acceso al mercado de los productos “orgánicos” (Ley núm. 20.089, D. Oficial de 17 de enero de 2006), la representación de las comunidades indígenas en comités consultivos para la cultura y las artes o la formación de fondos para promover la cultura de esos pueblos (Ley núm. 19.891, D. Oficial de 23 de agosto de 2003) y la participación indígena en las organizaciones comunitarias (Ley núm. 19.418, D. Oficial de 9 octubre de 1995)" ${ }^{\prime 0}$.

\footnotetext{
58 Cfr. Meza-Lopehandía, Matías (2009). Territorio y Autonomía de los Pueblos Originarios en Chile. Una mirada desde el ordenamiento jurídico chileno y la urgencia del Reconocimiento. Santiago, Tesis (Licenciatura en Ciencias Jurídicas y Sociales), Universidad de Chile, Facultad de Derecho, pp. 163-167.

59 Cfr. YÁÑez, Nancy (2004). Investigación Evaluativa de Impacto Ambiental en Territorios Indígenas. Disponible en: <http//www.observatorio.cl/contenidos/naveg/navContenido.php?c=2006020103264> [Consulta: 12 de abril 2013].

${ }^{60}$ NúÑEZ (2010), pp. 43-44.
} 
El reconocimiento constitucional de la diversidad cultural de Chile y, por ende de los pueblos indígenas, ha sido propuesto por parte del ejecutivo y de legisladores particulares al Congreso Nacional en múltiples oportunidades ${ }^{61}$. Sin embargo, todas ellas han tenido el mismo resultado: dilación y rechazo por parte de los partidos de la derecha chilena, en particular, de parte de la Unión Demócrata Independiente.

Reformar la Constitución, para incorporar el reconocimiento constitucional de los pueblos indígenas, es una de las principales demandas de los movimientos indígenas de Chile. Además, dicho punto ha sido recomendado y observado al Estado chileno por parte de organismos internacionales protectores de los derechos humanos ${ }^{62}$.

El Relator Especial sobre la situación de los derechos humanos y libertades fundamentales de los indígenas de las Naciones Unidas, en uno de sus informes sobre Chile, en el año 2003, señala como una de sus recomendaciones y hace un llamado al Congreso de Chile para que apruebe a la brevedad posible la iniciativa de reforma constitucional en materia indígena ${ }^{63}$.

Asimismo, en las propuestas del Informe final de la Comisión de Verdad Histórica y Nuevo Trato, se planteaba la necesidad de reformar la Constitución Política de la República, para que se reconociera constitucionalmente la diversidad cultural de Chile. En dicho informe, se señalaba lo siguiente:

\footnotetext{
${ }^{61}$ Sin ánimo exhaustivo, los proyectos de reforma constitucional más relevantes son: 1) Ingresada por el Presidente de la República, don Patricio Aylwin el 7 de enero de 1991 (Boletín No 513-07); 2) Presentada por el Diputado Francisco Huenchumilla, de la Democracia Cristiana, en el año 1999; 3) Presentada por el Presidente de la República, don Eduardo Frei Ruiz-Tagle, en el año 1999 y reimpulsada el año 2002 por el Presidente de la República don Ricardo Lagos Escobar; 4) Proyecto de reforma constitucional sobre reconocimiento de los pueblos indígenas, moción presentada por los senadores Andrés Allamand (RN), Carlos Cantero (RN), Alberto Espina (RN), José García (RN) y Sergio Romero (RN), el 6 de septiembre de 2007 y refundida con el mensaje presentado por la Presidenta doña Michelle Bachelet el 23 de noviembre de 2007 (Boletines Legislativos Nos. 5324-07 y 5522-07, refundidos), el que se encuentra actualmente en tramitación legislativa (primer trámite constitucional); 5) Proyecto de reforma constitucional sobre "participación y representación política de los pueblos indígenas", moción presentada por los diputados: Gonzalo Arenas (UDI), Pepe Auth (PPD), Fuad Chahín (DC), Alfonso de Urresti (PS), Enrique Jaramillo (PPD), Fernando Meza (PRSD), Cristián Monckeberg (RN), Guillermo Tellier (PC), Joaquín Tuma (PPD) y Orlando Vargas (PPD). Proyecto ingresado el 11 de julio de 2012 (Boletín No 8438-07), el que se encuentra actualmente en tramitación legislativa (primer trámite constitucional).

62 Véase: Consejo de Derechos Humanos, Naciones Unidas (2009). Informe del Relator Especial sobre la situación de los derechos humanos y las libertades fundamentales de los indigenas, James Anaya. La situación de los pueblos indigenas en Chile: Seguimiento a las recomendaciones hechas por el Relator Especial anterior. Disponible en: <http://daccess-dds-y.un.org/doc/UNDOC/GEN/G09/162/39/PDF/G0916239.pdf?OpenElement> [Consulta: 29 marzo 2014].

${ }^{63}$ Consejo de Derechos Humanos, Naciones Unidas (2003). Informe del Relator Especial sobre la situación de los derechos humanos y las libertades fundamentales de los indígenas, Sr. Rodolfo Stavenhagen, presentado de conformidad con la resolución 2003/56 de la Comisión. Disponible en: <http://daccess-dds-ny.un.org/doc/ UNDOC/GEN/G03/170/94/PDF/G0317094.pdf?OpenElement> [Consulta: 29 marzo 2013].
} 
"Perfeccionar la Constitución Política del Estado, introduciendo una regla incorporada en las Bases de la Institucionalidad, que:

-Declare la existencia de los Pueblos Indígenas, que forman parte de la nación chilena, y reconozca que poseen culturas e identidades propias.

-Declare que los Pueblos Indígenas de Chile son descendientes de las sociedades pre-coloniales que se desarrollaron en el territorio sobre el que actualmente el Estado chileno extiende su soberanía, a las que están ligados por una continuidad histórica. -Establezca el deber del Estado de garantizar la preservación de la diversidad étnico cultural de la nación y, por consiguiente, la preservación y el ejercicio de la cultura y la identidad de los Pueblos Indígenas, con pleno respeto a la autonomía de sus miembros; y que

-En consonancia con dicha declaración, reconozca y garantice el ejercicio de un conjunto de derechos colectivos a favor de los Pueblos Indígenas, de conformidad a las propuestas que en ese sentido se detallan más adelante"64.

Luego, la Comisión de Verdad Histórica y Nuevo Trato proponía dar rango constitucional a una serie de derechos colectivos, que son de participación política, culturales, derecho consuetudinario indígena y de protección de tierras y territorios. Esta propuesta, como tal, no se cristalizó en un proyecto de reforma constitucional concreto, es decir, que recogiera todos los aspectos de la misma y se puede considerar como la más completa y ambiciosa elaborada por una Comisión creada por el propio Estado.

Ahora bien, en cuanto a las propuestas que se han discutido en el Congreso Nacional surgen las siguientes preguntas: ¿Qué ópticas han seguido los proyectos de reforma constitucional, para el reconocimiento de la diversidad cultural de Chile? ¿Cuáles han sido los principales argumentos dados en el Congreso Nacional para no reformar la Constitución Política de la República, en el sentido de incorporar el reconocimiento constitucional de los pueblos indígenas?

Las propuestas que se han presentado hasta ahora, para el reconocimiento constitucional de los pueblos indígenas, han seguido dos visiones ideológicas distintas, aunque siempre transitando dentro del liberalismo, desde su versión clásica más arquetípica a una con tímidos rasgos de liberalismo cultural. El punto central y de principal tensión entre estas dos visiones es si se reconoce el sujeto colectivo de "pueblos indígenas" o el reconocimiento sólo es para incorporar a la Constitución la diversidad de origen de los chilenos ${ }^{65}$.

A la primera tendencia se puede sumar, en sus orígenes, el proyecto que presentó la Presidenta Michelle Bachelet durante su primer período y que se encuentra actualmente en tramitación. Sin embargo, con las indicaciones que éste ha sufrido, se podría señalar que se ha transformado en un proyecto híbrido jurídicamente, ya

${ }^{64}$ Egaña (2008), p. 535.

${ }^{65}$ Véase: Faundes, Juan (2004). "El Reconocimiento de los pueblos indígenas en Chile: una propuesta de reforma al Estado". En: Derechos Humanos y Pueblos Indígenas: Tendencias Internacionales y Contexto Chileno. Temuco: Instituto de Estudios Indígenas, Universidad de La Frontera, p. 302. 
que por un lado reconoce el sujeto colectivo "pueblos indígenas", pero al mismo tiempo señala que la "nación chilena es indivisible" 66.

Los argumentos utilizados por el bloque de derecha para no reconocer constitucionalmente a los pueblos indígenas ${ }^{67}$ han consistido en señalar lo inoficioso de ello, su preocupación por un posible movimiento separatista indígena ${ }^{68}$, la necesidad de unidad nacional ${ }^{69}$ y lo inconveniente del reconocimiento de derechos colectivos para los pueblos indígenas ${ }^{70}$. Además, estos argumentos ocultan la preocupación del sector sobre que el reconocimiento Constitucional, sumado a los Tratados Internacionales sobre la materia, puede llevar a que en Chile exista un cambio importante en materia de propiedad, siendo ello (desde su óptica) nocivo para el normal funcionamiento del mercado y de la economía nacional.

Así, la posición de la derecha chilena se ancla en los principios y valores establecidos en la Constitución de 1980 y ha usado todos los mecanismos contramayoritarios que ella franquea, para impedir que se reforme y se incorpore un reconocimiento constitucional a los pueblos indígenas.

Ahora bien, cabe la siguiente pregunta: ¿Las reformas constitucionales realizadas a la Constitución de 1980, más la normativa indígena señalada, han logrado cambiar la perspectiva al respecto? Desde la entrada en vigor la Constitución Política de 1980, el día 11 de marzo de 1981, ha sido objeto de múltiples reformas. En el año 1989, se introdujeron 54 enmiendas. Dentro de estas reformas está la del artículo $5^{\mathrm{o}}$ de la Constitución, al que se le incorporó el inciso $2^{\mathrm{o}^{71}}$. Mediante dicha reforma, según Francisco Cumplido, Ministro de Justicia del Presidente Aylwin y parte del grupo que negoció los cambios constitucionales con la Dictadura Militar, desde una posición iusnaturalista, expone sobre el sentido que le dieron al artículo $5^{\circ}$ precitado:

"Cuando estudié el problema, tuve presente que tanto en la Constitución de 1925, como en la de 1980, la doctrina incorporada a ellas era la de la existencia de los derechos

\footnotetext{
${ }^{66}$ Véase: Congreso Nacional, tramitación proyecto de ley, Boletines Nos. 5324-07 y 5522-07.

${ }^{67}$ Una exposición clara de la postura de la Derecha, la entrega el Senador Hernán Larraín, de la Unión Demócrata Independiente, durante la tramitación del proyecto de reforma constitucional, que se encuentra vigente. En la votación del proyecto de acuerdo, el día 17 de marzo del 2009. Ver: Congreso Nacional,

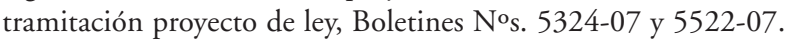

${ }_{68}$ Llama profundamente la atención que la derecha recurra tanto a este argumento, ya que él no tiene sentido jurídico alguno, salvo de tipo comunicacional, tomando en consideración que para el derecho internacional, es absolutamente claro que los pueblos indígenas no tienen derecho a la secesión, para un caso como el de Chile.

${ }^{69}$ Cfr. Pfeffer, Emilio (2005). Reformas Constitucionales 2005. Santiago: Editorial Jurídica de Chile, p. 546.

${ }^{70}$ Cfr. Pfeffer (2005), pp. 547-548.

${ }^{71}$ Sobre la discusión doctrinaria que ha originado el inciso $2^{\circ}$ del artículo $5^{\circ}$ de la Constitución Política, véase: Corvera, Diego (1999). "Constitución y Tratados sobre Derechos Humanos, el artículo 5o de la C.P. de 1980". En: Doctrinas Esenciales. Gaceta Jurídica, Derecho Constitucional. Santiago: Abeledo Perrot, pp. 1-20. Asimismo, véase: Tribunal Constitucional, Requerimiento de inconstitucionalidad, Rol № 346, 8 de abril de 2002 .
} 
humanos anteriores al Estado y que, por consiguiente, las Constituciones lo único que hacían era asegurarlos, y se asegura lo que ya existe. Ambas Constituciones, adhiriendo a la preexistencia de los derechos al Estado, los incorporaban a la Constitución para proclamarlos, protegerlos y promoverlos, al mismo tiempo que reglamentarlos en la normalidad y en las situaciones de excepción constitucional, como enseñaba mi maestro el Profesor Gabriel Amunátegui Jordán respecto de la Constitución de 1925. La Constitución de 1980 reforzó el carácter de los derechos humanos en el sistema constitucional chileno. En efecto, el inciso segundo del artículo $5^{\circ}$, establece, nada menos, que el ejercicio de la soberanía reconoce como limitación el respeto a los derechos esenciales que emanan de la naturaleza humana. Coloca pues sobre la soberanía a tales derechos. Por su parte, el Artículo $1^{\circ}$ prescribe que las personas nacen libres e iguales en dignidad y derechos, afirmación contenida en varias Convenciones sobre derechos humanos. Agrega que el Estado está al servicio de la persona humana. En la historia fidedigna de esta disposición constitucional quedó expresa constancia que la protección constitucional se refiere no sólo a los derechos establecidos en ella, sino a todos los que son inherentes a la naturaleza humana, como asimismo se reconoció que tales derechos no sólo son los enumerados en el texto de la Constitución, en los capítulos segundo y tercero, sino también los que formen parte del acervo cultural de la humanidad y que son propios de la naturaleza humana (Actas de la Comisión de la Nueva Constitución, sesión 203)"72.

Como se puede apreciar, la reforma en comento afianza la idea iusnaturalista de la Constitución, de su carácter prepolítico y que protege derechos -supuestamente- anteriores al Estado. Debiendo interpretarse el sentido dado a dichos derechos, que emanarían de la naturaleza humana, en la forma en que ellos fueron concebidos por los ideólogos de la Constitución, siendo las actas de la Comisión de estudios de la Nueva Constitución su expresión más fidedigna.

Me detengo en este punto, debido a que, a juicio de algunos autores, con la incorporación del inciso $2^{\circ}$ del artículo $5^{\circ}$ de la Constitución sería posible defender los derechos de los pueblos indígenas, ya que estos, en virtud de los tratados internacionales que versan sobre derechos humanos ${ }^{73}$, permitirían incorporar tales derechos a la Constitución ${ }^{74}$. Difiero de dicha interpretación, porque los derechos de los pueblos indígenas incorporados en los Tratados Internacionales colisionan permanentemente con el modelo político e ideológico creado por la Constitución de 1980, y con la reforma del artículo $5^{\circ}$ no se logra superar dicho marco. Ello se debe a que la reforma es coincidente con ella, y además porque los derechos indí-

\footnotetext{
72 Cumplido, Francisco (2003). "La reforma constitucional de 1989 al inciso $2^{\circ}$ del artículo 5 de la Constitución: sentido y alcance de la reforma. Doctrina y jurisprudencia”. Revista Ius et Praxis, año 9, No 1, pp. 365-374.

${ }^{73}$ Sobre la discusión que existe en la doctrina nacional, acerca de la jerarquía de los Tratados Internacionales que versan sobre derechos humanos y su incorporación al sistema de fuentes: Cfr. Cumplido (2003), pp. 365-374.

${ }^{74}$ En ese sentido, véase: MeZa-Lopehandía (2009), pp. 124-128.
} 
genas incorporados en los tratados sólo podrían desarrollar y ampliar los derechos fundamentales que la propia Constitución establece ${ }^{75}$.

Luego, durante los gobiernos de los presidentes Aylwin y Frei, se logró modificar el régimen de la administración local y regional, reducir el mandato presidencial de 8 a 6 años y aprobar una reforma al Poder Judicial, para la implementación de la Reforma Procesal Penal.

Sin embargo, pese a las reformas aprobadas, tal como señala Francisco Cumplido, al momento en que asumió el Presidente Ricardo Lagos, esto es el año 2000, subsistían importantes enclaves autoritarios ${ }^{76}$.

Así, en el año 2005, durante el mandato del Presidente Ricardo Lagos, se realizó una reforma constitucional mediante la cual se logró remover a los senadores designados y vitalicios; el poder de garante de la seguridad nacional a las Fuerzas Armadas; se reformó la integración, atribuciones y sistema de nombramiento de los ministros del Tribunal Constitucional; parcialmente, la composición del Senado.

Dichas reformas, junto a otras que se realizaron dicho año y que perfeccionan la democracia, instalaron el debate en el seno de la sociedad y en particular en la doctrina constitucional, si podíamos hablar de una nueva constitución o no.

En ese sentido el profesor Francisco Zúñiga propone para abordar el debate realizar una distinción de planos ${ }^{77}$. Un plano sería el político-institucional y el otro, el económico-social de la Constitución. En ese sentido:

"En el plano político-institucional la Constitución Política de la República es una 'nueva' Carta, ya que con la reforma constitucional de 2005 se cierra en lo formal la transición al purgar de la Constitución sus 'enclaves autoritarios', su estatuto iusfundamental transitorio, así como la firma puesta en el texto por el gobernante de la época, la Junta de Gobierno y sus ministros. En cambio en el plano económico-social (derechos civiles, orden público económico, Constitución Económica y Constitución Social) la Constitución vigente es en esencia la 'vieja' Carta de 1980, en la que cristalizan, principalmente en su parte dogmática (valores, principios, derechos fundamentales y garantías), los componentes ideológicos (originalmente autoritarios, neoliberales, iusnaturalistas, y lejanamente corporativistas) de una refundación autoritaria del capitalismo"78.

Así la constitución con las reformas incorporadas en el 2005 sigue siendo la vieja Constitución de 1980, ideada bajo los valores y prismas ideológicos ya señalados, que en lo social-económico proyecta y moldea un tipo de estado monocultural y neoliberal. Además, viendo el asunto según el prisma que plantea Fernando Atria,

\footnotetext{
75 En ese sentido, véase: Ruiz-Tagle, Pablo (2001). "Presentación: Constitucionalidad de los tratados internacionales en Chile". En: Los tratados internacionales en la jurisprudencia constitucional, Santiago: Fundación Facultad de Derecho, Universidad de Chile, pp. 5-15.

76 Cfr. Cumplido (2003), p. 2.

77 ZúNiga (2007), pp. 349-370.

78 ZÚNIGGA (2007), p. 351.
} 
la Constitución Política de 1980, pese a sus reformas (incluida la de 2005), sigue siendo la misma, ya que mantiene la neutralización de la agencia política del pueblo ${ }^{79}$.

Con ello, en lo que concierne a la apertura del techo ideológico de la Constitución, a la luz de las reformas que ha sufrido, en el plano de la multiculturalidad, en sus líneas gruesas, ella sigue anclada en los principios y valores construidos por los ideólogos de la Constitución de 1980. Bajo ese prisma, la legislación de tipo indígena que se ha aprobado desde 1990 en adelante busca incorporar una perspectiva pluralista cultural, de tipo liberal cultural atenuada, pero sus preceptos entran en colisión constantemente con una Constitución que busca idear una "nación" culturalmente igual, que reconoce derechos individuales e iguales (formalmente), sin derechos colectivos de grupo, donde uno de sus ejes fundamentales para el desarrollo económico social de quienes habitan el territorio es la propiedad privada, la libertad de empresa y la libre circulación de los bienes y la riqueza.

Además, la autodeterminación indígena choca frontalmente con una Constitución Política ideada para neutralizar la acción del pueblo en su conjunto y, por ende, de los indígenas y de los pueblos indígenas como tales (con mayor razón). Esta tensión se ve con claridad en el largo proceso de aprobación del Convenio No 169 de la OIT y en lo que ha sido su implementación en la práctica, todo ello, tomando en consideración que el Tribunal Constitucional, en los dos pronunciamientos que realizó al respecto, con el fin de compatibilizarlo con la Constitución, limitó el entendimiento del mismo en aspectos cruciales ${ }^{80}$.

\subsection{En materia inmigratoria}

Como Chile no ha sido históricamente un país receptor de migración, ha carecido de una política integral en la materia, reaccionando política y legislativamente a los fenómenos que causan la inmigración, más que a seguir algún tipo de política pública y legislativa que aborde el tema de forma general. La tendencia universal, a la hora de elaborar una política migratoria, es armonizar la capacidad institucional del país, la política pública y la necesaria protección de los derechos humanos de los migrantes. Sin embargo Chile, quizás por su condición de expulsor más que de polo de atracción, nunca ha tenido una política clara en esta materia. Más aún, documentos históricos hablan de consideraciones que podrían considerarse racistas y que tenían como fin dotar al país de una "estructura cultural superior".

En cuanto a la realidad actual de los inmigrantes en Chile, Macarena MACHIN, identificó que éstos son objeto de segregaciones de tipo laboral y espacial, de discriminaciones por su origen y sexo, precariedad laboral y de un desigual acceso a los servicios básicos ${ }^{81}$. Además, hace una síntesis de diversos estudios sociológicos

${ }^{79}$ Atria (2013a), p. 44.

${ }^{80} \mathrm{Al}$ respecto, véase: Meza-Lopehandía, Matías (2010). El Convenio No 169 sobre Pueblos Indígenas y Tribales en Paises Independientes en el sistema normativo chileno. Disponible en: <http://observatorio.cl.pampa. avnam.net/plibro/ficha/205> [Consulta: 13 marzo 2014].

${ }^{81}$ Cfr. MaChin (2011), pp. 42-46. 
realizados en Chile y que tienen que ver con la percepción que tienen los chilenos hacia los inmigrantes, la cual, en términos generales, es de rechazo ${ }^{82}$.

En el ámbito normativo ${ }^{83}$, y en primer lugar el constitucional, la Constitución de 1980, en su artículo $1^{\circ}$ preceptúa que el Estado está al servicio de la persona humana y su finalidad es promover el bien común, para lo cual debe contribuir a crear las condiciones sociales que permitan a todos y a cada uno de los integrantes de la comunidad nacional su mayor realización espiritual y material posible, con pleno respeto a los derechos y garantías que establece.

¿Qué entiende la Constitución por comunidad nacional? Al respecto, Macarena MACHIN señala que: "Comunidad nacional hace referencia a los miembros que conforman una Nación, ahora bien, este concepto tiene dos acepciones inseparables: la primera, en el ámbito del derecho político, hace referencia a la nación como el conjunto de sujetos políticos en quienes reside la soberanía constituyente de un Estado; la segunda acepción, es la que hace referencia a la nación cultural, concepto social e ideológico que define a una comunidad humana con ciertas características culturales comunes" ${ }^{\$ 4}$. Para ella, la Constitución tiene una concepción de comunidad nacional monocultural ${ }^{85}$.

Sin embargo, en la Constitución de 1980 se hizo una incorporación importante en materia de derechos para los inmigrantes. Ella dice relación con el reconocimiento al derecho de sufragio activo ${ }^{86}$ a los extranjeros ${ }^{87}$ que se avecinan en Chile

\footnotetext{
${ }^{82}$ Sobre la discriminación y falta de reconocimiento que viven a diario los inmigrantes (principalmente de origen andino) en Chile, véase: Polloni, Leonardo y MAtus, Christian (2011). Somos Migrantes. Experiencias de integración a la ciudad de Santiago. Santiago: Fundación Ideas, pp. 79-85.

${ }^{83}$ Para una completa recopilación y análisis de la normativa al respecto, véase: DONAIRE, Patricia (2013). "Efectos de la ratificación de los Tratados Internacionales de Derechos Humanos y Acuerdos Regionales en la legislación migratoria chilena”. En: Geografías de la espera. Santiago: Uqbar editores, pp. 31-62.

${ }^{84}$ Cfr. Machin (2011), p. 48.

${ }^{85}$ Anota, que es esta última acepción la que ha sido cuestionada por diversos países latinoamericanos (Bolivia, Ecuador y México, entre otros) cuya composición nacional se caracteriza por la pluralidad de culturas. El resultado de estas reivindicaciones es la elaboración de constituciones donde se reconoce explícitamente su composición como nación plurinacional, pluricultural o pluriétnica. MACHIN (2011), p. 48.

${ }^{86}$ Pablo Santolaya señala que el derecho a sufragio es una excepción a la universalización de los derechos humanos. Afirma que: "no existe ningún país en el mundo que reconozca incondicionalmente el derecho de sufragio activo y pasivo en todo tipo de elecciones a todos los extranjeros que se encuentren en su territorio. El punto más avanzado se encuentra en estos momentos, por una parte en Irlanda y Gran Bretaña, que proclaman tanto en su vertiente de sufragio activo como pasivo en todas las elecciones, pero exclusivamente para determinados tipo de extranjeros, por ejemplo, en el caso británico, los procedentes de Irlanda y de la Commmonwealth, que constituyen lo que podríamos denominar su comunidad histórica, y, por otra parte Chile y Uruguay que lo hacen de todos los extranjeros y en todos sus procesos electorales, pero exclusivamente en la vertiente de poder elegir, no de ser elegidos, y ligado, como en el caso de Uruguay, a periodos muy largos de residencia (...)". Cfr. SANTOloya, Pablo (2008). "El Derecho de sufragio de los extranjeros". Revista de Estudios Europeos, No 50, pp. 25-34.

${ }^{87}$ Sobre el derecho de voto de los extranjeros, desde una perspectiva comparada, consultar: Hervé, Andrés (2008). "El derecho de voto de los extranjeros en el ámbito universal". Revista de Derecho Migratorio y Extranjería, № 18, pp. 9-44.
} 
por más de cinco años, tal y como se contempla en el artículo 14 del texto original de la Carta Fundamental ${ }^{88}$.

De igual forma, en este punto, resulta bastante relevante la modificación constitucional realizada en 1989 al artículo 5º de la Constitución, ya analizada. Ello es importante, debido a que los derechos humanos son inherentes a todos, sin distinción de su origen nacional, por lo que los estados deben respetarlos, sin hacer distinciones de origen al respecto.

Completando el cuadro constitucional, hay que mencionar que el año 2005 se aprobó un nuevo inciso $2^{\circ}$ del artículo 14 de la Constitución, mediante el cual se permite que los extranjeros que hubieren obtenido una carta de nacionalización, puedan optar a cargos públicos de elección popular, después de cinco años de estar en posesión de su nacionalización.

En el plano de la normativa internacional, desde el año 1990, Chile ha tenido un proceso ascendente en la aprobación de Convenios Internacionales que abordan materias de inmigración. Aunque quedan muchos convenios y tratados relevantes que no han sido aprobados por Chile, uno de los hitos más importantes en esta materia viene dado por la aprobación por parte del Estado de Chile del Convenio para la protección de los derechos de todos los trabajadores migratorios y de sus familiares, de las Naciones Unidas, en el año 2005. En el marco de dicho convenio, Chile fue objeto de observaciones, realizadas por el Comité de protección de los derechos de todos los trabajadores migratorios y de sus familiares, de las Naciones Unidas, en el año 2011.

${ }^{88}$ La Constitución de 1980, en el artículo 14, en su texto original, estableció el derecho a sufragio para los extranjeros de la siguiente forma: "Artículo 14.- Los extranjeros avecindados en Chile por más de cinco años, y que cumplan con los requisitos señalados en el inciso primero del artículo 13, podrán ejercer el derecho de sufragio en los casos y formas que determine la ley". Ello constituyó una innovación, en relación a lo que contemplaba la Constitución Política de 1925, ya que ésta restringía el derecho a sufragio sólo a los ciudadanos chilenos. $\mathrm{Al}$ respecto el artículo $7^{\circ}$ señalaba: "Artículo 7.- Son ciudadanos con derecho a sufragio los chilenos que hayan cumplido 18 años de edad y estén inscritos en los registros electorales”. En la Sesión No 72 de la Comisión Ortúzar, celebrada el 23 de septiembre de 1978, Jaime Guzmán entrega su fundamentación para esta innovación constitucional, y como se podrá ver, tiene relación con la búsqueda de conceder derecho a voto a aquellos extranjeros "ilustres" y "destacados", principalmente europeos, que llevan mucho tiempo en el país y que no están dispuestos a renunciar a su ciudadanía de origen para adquirir la chilena. Al respecto en las actas de la Comisión Ortúzar se señaló lo siguiente: “(...) el señor Guzmán manifiesta que correspondería consagrar la excepción y propone que se consigne que, con todo, los extranjeros tendrán derecho a sufragio en determinadas condiciones. Le parece que, desde el punto de vista doctrinario, indiscutiblemente se complica este aspecto, porque no hay duda que, si la ciudadanía es una calidad que tienen determinados nacionales y de ella emanan determinados derechos de los cuales todavía se substraerá a ciertos ciudadanos, todo el tema sigue una línea cada vez más restrictiva hasta llegar al derecho de sufragio, del cual estarán privados algunos nacionales e, incluso, algunos ciudadanos. O sea, desde el punto de vista de la doctrina, rompe la armonía tradicional; pero, desde un punto de vista práctico, le parece que el hecho de que determinados extranjeros con hondo arraigo en la vida del país por su larga permanencia en él puedan votar, es un hecho positivo para la vida cívica. En ese sentido -agrega- entre un doctrinarismo puro y las ventajas prácticas para la vida cívica, prefiere otorgar el derecho a voto a los extranjeros en determinadas condiciones". En: BiblioteCA DEL CONGRESO NACIONAL DE ChIle. Historia de la Ley. Constitución Politica de la República de Chile de 1980, Artículo 14. Disponible en: <http://www.leychile.cl/Navegar?idNorma=242302\&eh=True> [Consulta: 19 marzo 2013]. 
Junto a lo anterior, se deben tener en cuenta los acuerdos de libre comercio firmados por Chile, los que han incorporado cláusulas tendientes a disminuir las barreras que impiden la movilidad entre países con intereses comunes. Así, en los tratados suscritos con: Canadá, México, Centroamérica, Corea y la Unión Europea, se contemplan capítulos que regulan la entrada de profesionales y capitales, permitiendo de paso incrementar mutuamente niveles de productividad, así como la creación de empleos, a través de la llegada de inversionistas. De igual forma, los acuerdos y los procesos de integración regional han abordado aspectos migratorios, generando espacios comunes para los nacionales del Mercado Común del Sur (MERCOSUR), la Comunidad Andina de Naciones y la Unión de Naciones Suramericanas (UNASUR).

En lo que se refiere a la regulación de rango legal, paradójicamente y a diferencia de lo que se ha expuesto en relación a los pueblos indígenas, la primera regulación importante en materia de inmigración fue dictada por la Dictadura Militar y es el Decreto Ley No 1.094 de 1975, conocido como Ley de Extranjería, al que se le han introducido numerosas modificaciones con el objeto de hacer la norma coherente con los Derechos Humanos y los fenómenos globalizadores y de integración mundial actual.

En ese sentido, la Ley No $19.476^{89}$, de octubre de 1996, modificó la Ley de Extranjería en materia de asilo y refugio, reconociendo el principio de no devolución de quienes se encuentran en Chile solicitando dicha condición. Del mismo modo, despenaliza el ingreso irregular al territorio nacional de extranjeros que soliciten refugio o asilo, entre otras garantías.

En 1998, se aprueba y publica la Ley No $19.581^{90}$, que crea la categoría de ingreso de habitante de zona fronteriza, con lo que quienes se encuentren en esta situación pueden obtener una "Tarjeta vecinal fronteriza" mediante la cual se les otorga la facilidad de ingresar y egresar de Chile sólo con su presentación a las autoridades fronterizas.

Además, se debe tener en consideración para el análisis, la aprobación reciente ${ }^{91}$ de la Ley Antidiscriminación (Boletín No 3815-07), que señala en su artículo 1º, inciso primero, que la ley tiene por objetivo fundamental "instaurar un mecanismo judicial que permita restablecer eficazmente el imperio del derecho toda vez que se cometa un acto de discriminación arbitraria”. Asimismo, la ley establece en su artículo $1^{\circ}$, inciso $2^{\circ}$, que: "Corresponderá a cada uno de los órganos de la Admi-

${ }^{89}$ Ley No 19.476, introduce modificaciones al Decreto Ley No 1.094, de 1875, en materia de refugiados, Diario Oficial, 21 de octubre de 1996.

${ }^{90}$ Ley No 19.581, establece categorías de habitantes de zonas fronterizas, Diario Oficial, 1 de septiembre de 1998.

${ }^{91}$ Ley No 20.069, establece medidas contra la discriminación, Diario Oficial, 24 de julio de 2012. La Ley Antidiscriminación fue aprobada en una dividida votación en el Senado el día 9 de mayo del año 2012. El Proyecto de Ley fue presentado por el Presidente don Ricardo Lagos Escobar, el 14 de marzo del año 2005. 
nistración del Estado, dentro del ámbito de su competencia, elaborar e implementar las politicas destinadas a garantizar a toda persona, sin discriminación arbitraria, el goce y ejercicio de sus derechos y libertades reconocidos por la Constitución Politica de la República, las leyes y los tratados internacionales ratificados por Chile y que se encuentren vigentes".

En el artículo $2^{\circ}$ de la ley en comento, se define por discriminación arbitraria "toda distinción, exclusión o restricción que carezca de justificación razonable, efectuada por agentes del Estado o particulares, y que cause privación, perturbación o amenaza en el ejercicio legitimo de los derechos fundamentales establecidos en la Constitución Política de la República o en los tratados internacionales sobre derechos humanos ratificados por Chile y que se encuentren vigentes, en particular cuando se funden en motivos tales como la raza o etnia, la nacionalidad, la situación socioeconómica, el idioma, la ideología u opinión politica, la religión o creencia, la sindicación o participación en organizaciones gremiales o la falta de ellas, el sexo, la orientación sexual, la identidad de género, el estado civil, la edad, la filiación, la apariencia personal y la enfermedad o discapacidad'.

Así, con la nueva Ley Antidiscriminación los extranjeros podrán ejercer la acción de no discriminación arbitraria, establecida en los artículos $3^{\circ}$ y siguientes, cada vez que sean objeto de una discriminación arbitraria y, por ende, solicitar en conformidad al artículo 12, que se deje sin efecto el acto discriminatorio y que el Juez decrete las providencias que juzgue necesarias para restablecer el imperio del derecho y asegurar la debida protección del afectado.

La actual normativa migratoria ha sido objeto de críticas, principalmente debido a su marcado acento en la seguridad nacional, la excesiva participación policial y arbitrariedad de las autoridades nacionales ${ }^{92}$, las carencias de su sistema institucional y su incapacidad para tender a la inclusión de los migrantes a la sociedad chilena ${ }^{93}$.

Con el fin de corregir la deficiente normativa migratoria expuesta, el 4 de junio de 2013, el Gobierno del Presidente Sebastián Piñera, ingresó al Congreso Nacional un proyecto de Ley de Migración y Extranjería. La modificación legal de la actual normativa en materia migratoria era una demanda que venían realizando hace años organizaciones de migrantes y organismos no gubernamentales que trabajan en el área. El proyecto de ley presentado toma en consideración la realidad migratoria por la que atraviesa Chile y según su mensaje busca: "aprovechar las potenciales

\footnotetext{
92 Cfr. Moller, Franz, Caucoto, Nelson y Godoy, Rodrigo (2013). “Oficina especializada de Derechos Humanos de la Corporación de Asistencia Judicial: Solicitud al Pleno de la Corte Suprema por grave situación que afecta a los extranjeros en Chile". En: Un Chile abierto: propuestas para una nueva ley de migración, No 2, Santiago: Centro de Democracia y Comunidad, pp. 62-87.

${ }^{93}$ Cfr. Torrealba, Nicolás (2013). "Mínimos regulatorios para una nueva y mejorada ley de extranjería". En: Un Chile abierto: propuestas para una nueva ley de migración, $N^{\circ}$ 2. Santiago: Centro de Democracia y Comunidad, pp. 9-16. Asimismo, véase: Donaire, Patricia y Cubides, José (2013). "Consideraciones y problemáticas que debiera regular una nueva ley de extranjería”. En: Un Chile abierto: propuestas para una nueva ley de migración, No 2, Santiago, Centro de Democracia y Comunidad, pp. 88-105.
} 
ventajas de la migración internacional en beneficio del país. En la línea de países como Canadá, Estados Unidos, Australia y Nueva Zelanda, que han forjado buena parte de su desarrollo en base al aporte de la población foránea, se concibe la ley como una herramienta capaz de atraer talento y fuerza laboral en sectores y lugares determinados" $"$.

Sin embargo, el proyecto de ley es criticable debido a que no ayuda en la adecuada protección de los derechos humanos de los inmigrantes, omitiendo obligaciones internacionales del Estado y desconociendo los instrumentos internacionales de integración regional que ha suscrito Chile ${ }^{95}$. Asimismo, no toma en consideración la capacidad estatal para autorizar la residencia de extranjeros en el país, continúa con el amplio margen de discrecionalidad del ejecutivo en la expulsión de extranjeros e "intenta importar mecanismos vigentes en Estados con otras dinámicas migratorias y cuerpos consulares muy diferentes" ${ }^{\prime 9}$.

\section{CONCLUSiOnes}

La actual Constitución Política de la República, pese a las múltiples reformas que ha experimentado, tiene límites ideológicos que no le permiten acoger la diversidad cultural. En materia indígena, no posee norma alguna que recoja los derechos de los indígenas y de sus pueblos. En materia inmigratoria, su normativa es deficiente en el hecho de incorporar una perspectiva del fenómeno multicultural en su inspiración.

Lo anterior no puede ser considerado una virtud, sino que todo lo contrario. Con el presente trabajo, he pretendido demostrar que, en el plano teórico, existe una especie de consenso sobre la importancia normativa del reconocimiento de la diversidad cultural entre las principales corrientes teóricas vigentes (liberalismo, comunitarismo e interculturalismo). Así, nuestra Constitución Política y la institucionalidad se encontrarían al margen de ello y anclada en posturas ya superadas. De igual forma, nuestra Constitución se encuentra alejada de la tendencia del

\footnotetext{
${ }^{94} \mathrm{El}$ proyecto señala que la actual normativa tiene una serie de insuficiencias, tales como: 1) carencia de principios orientadores, derechos y deberes; 2) Sus categorías migratorias son insuficientes; 3) Institucionalidad débil; 4) Ausencia de mecanismos institucionales para la generación de política; 5) Omisión de toda referencia a los chilenos que viven en el exterior; 6) Dificultad para la expulsión; 7) Dificultad para la revalidación de títulos universitarios; 8) Limitación a la contratación de trabajadores extranjeros; 9) Dificultad para el tránsito vecinal fronterizo. Véase: Mensaje de S.E. el Presidente de la República con el que inicia un proyecto de ley de migración y extranjería, No Boletín 8970-06, disponible en: http://www. camara.cl/pley/pley_detalle.aspx?prmID=9377\&prmBL=8970-06. Para un análisis crítico del proyecto de ley, véase: OlEA, Helena (2013). "Derechos Humanos de los migrantes y refugiados. Análisis del proyecto de ley de migración y extranjería”. En: Informe anual sobre los Derechos Humanos en Chile 2013, Santiago: Universidad Diego Portales, pp. 123-162.

95 Olea (2013), p. 159.

${ }^{96}$ Olea (2013), p. 127.
} 
constitucionalismo latinoamericano y en una tensión importante con el Derecho Internacional de los Derechos Humanos en la materia.

Dicho lo anterior, considero que el reconocimiento constitucional de la diversidad cultural en Chile debería realizarse contemplando dos objetivos, que son complementarios e igualmente importantes. Estos serían: 1) Proceso de diálogo y consulta amplio; 2) Reforma sustantiva en materia de multiculturalidad.

El primero de ellos dice relación con el proceso de reforma de la Constitución, para el reconocimiento de la diversidad cultural. Dicho proceso debería realizarse dentro de un amplio diálogo y consulta con los pueblos indígenas y otras minorías culturales. Para su desarrollo, se deberían ocupar los parámetros señalados en el Convenio No 169 de la OIT, para el desarrollo de la consulta.

Para asegurar una "efectiva participación" de los pueblos indígenas y minorías culturales, el Estado tiene el deber de consultar activamente con ellos según sus costumbres y tradiciones, aceptar y brindar información, y promover la comunicación constante entre las partes. Las consultas deben realizarse de buena fe, a través de procedimientos culturalmente adecuados, y deben tener como fin llegar a un acuerdo.

Junto a lo anterior, éste es uno de los temas que se suele llamar como "de Estado", es decir, que requiere la participación y consenso del amplio espectro político, o al menos de las grandes mayorías. Por ello, es fundamental que la derecha chilena pueda ampliar sus horizontes en el debate y revisar los planteamientos que desde su propia filosofía política (el liberalismo) hacen autores como KYMLICKA.

Como segundo aspecto a considerar, la reforma a la Constitución que contemple un reconocimiento de la multiculturalidad debe ser sustantiva e ir acompañada de un cambio en la práctica institucional y social. Si ello no ocurre, se corre el riesgo de que se transforme en una reforma de carácter simbólico y su discurso se disocie de la realidad ${ }^{97}$.

Por reforma sustantiva a la Constitución en esta materia, entiendo aquella que busque el reconocimiento constitucional de la diversidad cultural de Chile y contemple medidas concretas de reparación en el plano de reconstrucción de la comunidad indígena en torno a sus tierras ancestrales.

Para lo anterior, la reforma a la Constitución, en primer lugar, debiera contemplar, dentro de las bases de la institucionalidad, un reconocimiento de que Chile es un país multicultural, que se encuentra compuesto por múltiples culturas y naciones, dentro de las cuales están los pueblos indígenas ancestrales.

En segundo lugar, debiera establecer el deber del Estado de preservar y garantizar la diversidad étnica cultural del país, es decir, reconozca el derecho a la "supervivencia cultural". En este punto, se incluyen: 1) Los derechos de educación y el respectivo respeto a la diversidad cultural; 2) El reconocimiento constitucional de

${ }^{97} \mathrm{Al}$ respecto, véase: AYLWIN, José (2013). "Igualdad, inclusión y pueblos indígenas: entre el discurso y la política pública”. En: Igualdad, inclusión y derecho, Santiago: Lom Ediciones, pp. 129-151. 
oficialidad de los idiomas y lenguas de los pueblos indígenas; 3) Reconocimiento y protección de las prácticas culturales y económicas de los pueblos indígenas y otras minorías culturales.

En tercer lugar, debería consagrar derechos de grupo o colectivos, que dicen relación a derechos de representación política de los grupos culturales en los espacios de elección popular y las instituciones públicas. Con ello, se busca que el Estado en su conjunto tenga representación de la diversidad cultural en las instituciones que lo conforman, para que las políticas que elaboren no sean heterónomas para los grupos culturales y contemplen su visión de las cosas.

En cuarto lugar, debiera consagrar derechos colectivos, en lo que respecta a la propiedad indígena y la especial relación de ellos para con la tierra y el medio natural. En este punto, como parte del desarrollo legislativo, se debe establecer la propiedad de los pueblos indígenas sobre los recursos naturales que se encuentran dentro de sus áreas de desarrollo y, por ende, dictar legislación especial de protección de los mismos.

En quinto lugar, debiera establecer un mecanismo constitucional especial de expropiación de tierras que se encuentran en propiedad de particulares y que serían parte de las tierras ancestrales de las comunidades indígenas a restituir.

En sexto lugar, debiera contemplar el reconocimiento del pluralismo jurídico en la Constitución. Entendiéndolo en un sentido amplio, es decir, en cuanto a la facultad para crear norma jurídica y adjudicarla, estableciendo como límite los derechos establecidos en la Constitución y la protección de los derechos humanos.

Como sexto y último punto, la reforma debiera asegurar el efectivo y real goce de los derechos fundamentales a la totalidad de los habitantes de la República, ya sean estos chilenos, indígenas o extranjeros avecindados en nuestro país.

Finalmente, es importante considerar que una reforma constitucional de la índole reseñada, manteniendo dentro de la Constitución el principio de subsidiariedad, el "orden público económico" y la "neutralización” de la agencia del pueblo podría resultar inoficioso y de muy difícil compatibilidad. Por ello, necesariamente, una reforma de este tipo pasa por una apertura completa del techo ideológico de la Constitución, a través de una operación constituyente (Asamblea Constituyente) que dentro de sus tópicos contemple el reconocimiento de la multiculturalidad y establezca una nueva Constitución Política en Chile. 